\title{
Assessing the Climate Monitoring Utility of Radio Occultation Data: From CHAMP to FORMOSAT-3/COSMIC
}

\author{
Ulrich Foelsche $^{1, *}$, Barbara Pirscher ${ }^{1}$, Michael Borsche ${ }^{1}$, Gottfried Kirchengast ${ }^{1}$, and Jens Wickert ${ }^{2}$ \\ ${ }^{1}$ Wegener Center for Climate and Global Change (WegCenter) and Institute for Geophysics, Astrophysics, and Meteorology (IGAM), \\ University of Graz, Graz, Austria \\ ${ }^{2}$ Helmholtz Centre Potsdam, GFZ German Research Centre for Geosciences, Potsdam, Germany
}

Received 27 June 2007, accepted 14 January 2008

\begin{abstract}
Radio Occultation (RO) data, using Global Positioning System (GPS) signals, deliver high quality observations of the atmosphere, which are well suited for monitoring global climate change. The special climate utility of RO data arises from their accuracy and long-term stability due to self-calibration. Launched in 2000, the German research satellite CHAMP (CHAllenging Minisatellite Payload for geoscientific research) provides the first opportunity to create RO based climatologies. Overlap with data from the Taiwan/US FORMOSAT-3/COSMIC (Formosa Satellite Mission 3/Constellation Observing System for Meteorology, Ionosphere and Climate, F3C) mission allows the testing for consistency of climatologies derived from different satellites. We show initial results for zonal mean climatologies as well as tropical tropopause parameters based on F3C RO data. Our results indicate excellent agreement between RO climatologies from different F3C satellites as well as between data from different RO missions. After subtraction of the estimated respective sampling error, seasonal temperature climatologies derived from different $\mathrm{F} 3 \mathrm{C}$ satellites are in agreement to within $<0.1 \mathrm{~K}$ almost everywhere in the considered domain between 8 and $35 \mathrm{~km}$ altitude. Monthly mean tropical tropopause (lapse rate) temperatures and altitudes derived from four different RO missions show remarkable consistency $(<0.2-0.5 \mathrm{~K},<50-100 \mathrm{~m})$ and indicate that data from different RO missions can indeed be combined without need for inter-calibration. F3C final constellation sampling error estimation shows a small oscillating local time related error $( \pm 0.03 \mathrm{~K}$ amplitude $)$ in the extratropics.
\end{abstract}

Key words: Climate monitoring, Radio occultation, Upper troposphere, Lower stratosphere

Citation: Foelsche, U., B. Pirscher, M. Borsche, G. Kirchengast, and J. Wickert, 2009: Assessing the climate monitoring utility of radio occultation data: From CHAMP to FORMOSAT-3/COSMIC. Terr. Atmos. Ocean. Sci., 20, 155-170, doi: 10.3319/TAO.2008.01.14.01(F3C)

\section{INTRODUCTION}

Accurate, consistent long-term data are required as basis for climate studies and for attempts to detect, understand, and attribute climate variability and change. Our knowledge about the temperature evolution in the free atmosphere is still limited, despite notable endeavors to build long term upper air temperature records. This has been done using data from MSU (Microwave Sounding Unit) as well as AMSU (Advanced MSU) instruments on board polar orbiting satellites (e.g., Christy and Spencer 2005; Mears and Wentz 2005; Vinnikov et al. 2006) as well as using data from radiosondes (e.g., Sherwood et al. 2005; Thorne et al. 2005). After many years of intense discussions, temperature trend

\footnotetext{
* Corresponding author

E-mail:ulrich.foelsche@uni-graz.at
}

estimates based on these data sets now seem to be consistent with surface warming estimates and results from climate models but significant discrepancies still remain (Karl et al. 2006). Independent high-quality upper air records are therefore desirable.

A promising source for such data sets is the Global Positioning System (GPS) Radio Occultation (RO) technique, combining high accuracy and vertical resolution, long-term stability due to intrinsic self calibration, global coverage, and all-weather capability. The RO technique was originally developed for the study of planetary atmospheres and ionospheres (see Yunck et al. 2000, for a review). Sensing of the Earth's atmosphere with RO data was demonstrated with the GPS Meteorology (GPS/MET) experiment within several measurement campaigns from April 1995 to March 1997, 
proving most of the expected strengths of the technique, like high vertical resolution, high accuracy of retrieved parameters, and insensitivity to clouds (Ware et al. 1996; Kursinski et al. 1997; Rocken et al. 1997; Steiner et al. 1999). The German research satellite CHAMP (CHAllenging Minisatellite Payload for geoscientific research) was launched in July 2000, continuous RO measurements started in August 2001 (Wickert et al. 2001, 2004). CHAMP RO data provide the first opportunity to create RO based multiyear climatologies.

In April 2006, FORMOSAT-3/COSMIC (Formosa Satellite Mission 3/Constellation Observing System for Meteorology, Ionosphere, and Climate, F3C), a Taiwan/US RO mission consisting of six receiving satellites (Rocken et al. 2000; Wu et al. 2005; Schreiner et al. 2007) was successfully launched, providing up to $\sim 2500 \mathrm{RO}$ profiles per day. All six F3C satellites were launched from a single launch vehicle into a parking orbit with $\sim 515 \mathrm{~km}$ orbit altitude. The satellites have been sequentially raised to their final orbit altitudes of $\sim 800 \mathrm{~km}$. At this altitude the precession due to the oblateness of the Earth is smaller than in the parking orbit [see section 3.4, Eq. (2)], leading to a (desired) deployment of the orbit planes to a final separation of $30^{\circ}$. By the end of 2007 five of the six F3C satellites have reached their final orbits.

The potential of RO data for climate monitoring has been shown based on simulation studies (e.g., Yuan et al. 1993; Steiner et al. 2001; Foelsche et al. 2003; Leroy et al. 2006) and through climatological analyses (Schroeder et al. 2003; Hajj et al. 2004; Gobiet et al. 2005; Foelsche et al. 2006, 2008; Schmidt et al. 2006; Borsche et al. 2007; Schreiner et al. 2007). Here we report initial results on climate monitoring with $\mathrm{F} 3 \mathrm{C}$ RO data. The $\mathrm{F} 3 \mathrm{C}$ data base is certainly still too small for extensive climatological analyses, but sufficient to test the consistency of climatologies from different F3C satellites and the consistency with climatologies derived from CHAMP RO data. Also a few "anchor point" months from the RO satellites SAC-C and GRACE are compared. In section 2 we describe the setup of F3C RO climatologies. In section 3 we present and discuss initial results on $\mathrm{F} 3 \mathrm{C}$ climatologies, tropical tropopause parameters, and simulation results for the $\mathrm{F} 3 \mathrm{C}$ sampling error (in its final orbit constellation) due to uneven local time sampling, followed by concluding remarks.

\section{METHODS AND DATA}

A detailed description of the RO technique is given by Kursinski et al. (1997), Steiner et al. (2001), and Hajj et al. (2002).

\subsection{Profile Retrieval}

Within the CHAMPCLIM project (Foelsche et al. 2005), a cooperative endeavor by the Wegener Center in Graz and the GeoForschungsZentrum (GFZ) in Potsdam, a retrieval scheme has been developed at the Wegener Center (Gobiet and Kirchengast 2004; Borsche et al. 2006; Gobiet et al. 2007; Foelsche et al. 2008), with a special focus on minimizing potential biases of atmospheric parameters and on using background information in a transparent way. The same retrieval scheme, in an upgraded version (improved outlier rejection, noise filtering, and Earth reference surface), now termed Occultation Processing System version 5.2 (OPSv5.2), has been applied to all RO data used in this study (F3C, CHAMP, GRACE, and SAC-C).

OPSv5.2 is based on geometric optics and ionospheric correction via a linear combination of bending angles (Vorob'ev and Krasil'nikova 1994) and starts from RO phase delay data for each occultation event including precise position and velocity information for the transmitting and receiving satellites. At high altitudes, where the errors in RO data are comparatively large, the retrieved bending angle profiles are combined with bending angle profiles derived from background information in a statistically optimal way, using the inverse covariance weighting approach (Healy 2001) to minimize residual biases in atmospheric parameters below $35 \mathrm{~km}$ (Gobiet and Kirchengast 2004; Gobiet et al. 2007). As background information we use what we regard as the best available dataset, the operational analyses from the European Centre for Medium-Range Weather Forecasts (ECMWF). For each observed RO profile, collocated atmospheric parameters are extracted from the temporally closest of the six-hourly ECMWF analysis fields and expanded upwards from $\sim 60$ to $120 \mathrm{~km}$ using MSISE-90 climatology (Hedin 1991). The OPSv5.2 atmospheric profiles are background-dominated above the stratopause and observationdominated below $40 \mathrm{~km}$. Our approach results in well defined error characteristics and allows to initialize the hydrostatic integral at very high altitudes $(120 \mathrm{~km})$, where the upper-boundary initialization has no effect on the retrieved atmospheric parameters in the height interval of interest (below $40 \mathrm{~km}$ ).

A dry air retrieval (Syndergaard 1999; Gobiet et al. 2007) is used to derive atmospheric parameters, yielding "dry temperature", which is a commonly used variable in the RO community. At altitudes above $8 \mathrm{~km}$ (polar winter) and $14 \mathrm{~km}$ (tropics) the difference between "dry" and physical temperature is always well below $0.1 \mathrm{~K}$ (for a detailed discussion see Foelsche et al. 2008). In this regard, Steiner et al. (2007) also recently inspected the effect of using "dry" instead of physical temperatures related to a comparison of RO-derived synthetic MSU TLS data (upper troposphere/ lower stratosphere temperatures; also called T4 channel data) with the real MSU climate records. Based on checks with ECMWF analysis data, using both dry and physical temperature profiles over the full time period 2001 - 2006, they found negligible difference in the RO-derived MSU 
TLS temperatures of $<0.02 \mathrm{~K}$ in the tropics and of $<0.01 \mathrm{~K}$ globally and in the extratropics, respectively.

The basic retrieval scheme (before the upgrade to OPSv5.2) has been validated with five different atmospheric analyses and independent data sets (such as from MIPAS on Envisat). The results indicate that the global mean RO temperature error between 10 and $30 \mathrm{~km}$ altitude is $<0.2 \mathrm{~K}$. Residual biases in latitudinally resolved climatologies as used here are observationally constrained by this validation to $<0.5 \mathrm{~K}$ up to $30 \mathrm{~km}$ in any case, even if severely biased (about $10 \mathrm{~K}$ or more) a priori information is used in the high altitude initialization of the retrieval (Gobiet et al. 2007).

\subsection{Setup of Climatologies}

For the setup of RO climatologies we used the same approach as explained in detail by Foelsche et al. (2008). Our RO climatologies are obtained by "binning and averaging". All RO profiles in a prescribed geographic domain ("bin") are sampled and averaged (weighted by the cosine of the latitude), using a common (mean-seal-level, MSL) altitude grid with a regular $200 \mathrm{~m}$ spacing of altitude levels. The mean dry temperature profile in each bin is

$$
\overline{T_{\mathrm{dry}}(z)}=\frac{1}{\sum_{i=1}^{N_{\text {pof }}(z)} \cos \left(\varphi_{i}\right)} \sum_{i=1}^{N_{\text {porf }}(z)} T_{\mathrm{dry}}\left(z, \varphi_{i}\right) \cos \left(\varphi_{i}\right)
$$

where $N_{\text {prof }}(z)$ is the number of profiles in each bin at level $z$, which decreases with decreasing altitude in the troposphere. The cosine-weighting accounts for area changes between meridians at varying latitudes. We use "fundamental" zonal bins with $5^{\circ}$ latitudinal width to build zonal mean monthly climatologies. Our basic latitudinal resolution (used for the results shown here) is $10^{\circ}$, each of the 18 latitude bands (pole to pole) contains two fundamental bins, and the mean profiles for these two bins are averaged, weighted with the surface area of the respective bin. This approach slightly reduces the effect of uneven sampling within the latitude bands. Seasonal climatologies are obtained by averaging over three monthly climatologies. A finer longitudinal resolution is feasible (e.g., for the entire F3C constellation) but not recommended for single-satellite climatologies (Foelsche et al. 2008).

The total error of RO climatologies can be separated into an observational component (dominated by the systematic error) and a sampling error component due to an undersampling of the true spatial and temporal variability of the atmosphere (Foelsche et al. 2006, 2008; Pirscher et al. 2007). Even with perfect observations (without any observational errors), climatologies from different RO sensors would differ due to different sampling of the atmosphere and both would differ from the "true" mean state of the atmosphere. The sampling error can be quantitatively estimated, when an adequate representation of the "true" spatio-temporal evolution of the atmosphere is available and the times and locations of RO events are known (even for future RO missions, see section 3.4). As a proxy for this atmospheric evolution we use ECMWF analyses, which are obtained by dynamically combining a short-range forecast with data from virtually all traditional sources (like radiosondes and MSU/AMSU satellite instruments) via four-dimensional variational assimilation (ECMWF 2004). ECMWF analyses are available at four time layers per day $(0000,0600$, 1200 , and 1800 UTC), which is sufficient to sample the diurnal cycle up to the second harmonic (the semidiurnal cycle). We estimate the sampling error by comparing climatologies derived from vertical ECMWF profiles at the RO times and locations (the mean tangent point location) with climatologies derived from the complete 4D ECMWF field (see Foelsche et al. 2008, for further details).

\section{RESULTS AND DISCUSSION}

\subsection{Monthly Climatologies}

In this section we show exemplary monthly climatologies for September 2006. The vertical range of all fields shown extends from 0 to $35 \mathrm{~km}$ altitude. The CHAMP climatologies are cut off at the lower end at varying heights increasing from the poles toward the equator. From the poles to $60^{\circ}$ latitude they reach down to $4 \mathrm{~km}$, the cut-off height then increases over the mid latitude bins to $8 \mathrm{~km}$ at low latitudes (from the equator to $30^{\circ}$ north and south). Within $60^{\circ}$ to $30^{\circ}$ the cut-off heights are $5 \mathrm{~km}\left(60^{\circ}-50^{\circ}\right)$, $6 \mathrm{~km}\left(50^{\circ}-40^{\circ}\right)$, and $7.5 \mathrm{~km}\left(40^{\circ}-30^{\circ}\right)$. The reason for this strategy is to disregard regions with biased sampling in the lower troposphere caused by different penetration depths of the individual CHAMP profiles (see Foelsche et al. 2008). Our preliminary $\mathrm{F} 3 \mathrm{C}$ climatologies are cut-off at $8 \mathrm{~km}$, since open loop processing is not included yet.

The 18 zonal bands and the geographic distribution of all $\sim 31000 \mathrm{~F} 3 \mathrm{C}$ events (that passed quality control) are shown in Fig. 1a in an equal-area map projection. The CHAMP climatology involves 4166 events. Due to the high inclination $\left(72^{\circ}\right)$ of all six F3C satellites, $\mathrm{RO}$ events are globally distributed, but the event density at low latitudes is comparatively low. The inclination is, on the other hand, not high enough (together with a $55^{\circ}$ inclination of the GPS satellites) to allow for many $\mathrm{RO}$ events beyond $85^{\circ}$ latitude, resulting in systematically uneven sampling in the northernmost and southernmost (polar cap) bin, respectively. The F3C dry temperature climatology is displayed in Fig. 1b, showing distinct features like the cold tropical tropopause region and the cold Antarctic polar vortex.

The estimated sampling error for $\mathrm{F} 3 \mathrm{C}$ and CHAMP is shown in Figs. 1c and d, respectively. In September 2006 all 
(a) Sep 2006 : Formosat-3/COSMIC Event Distribution

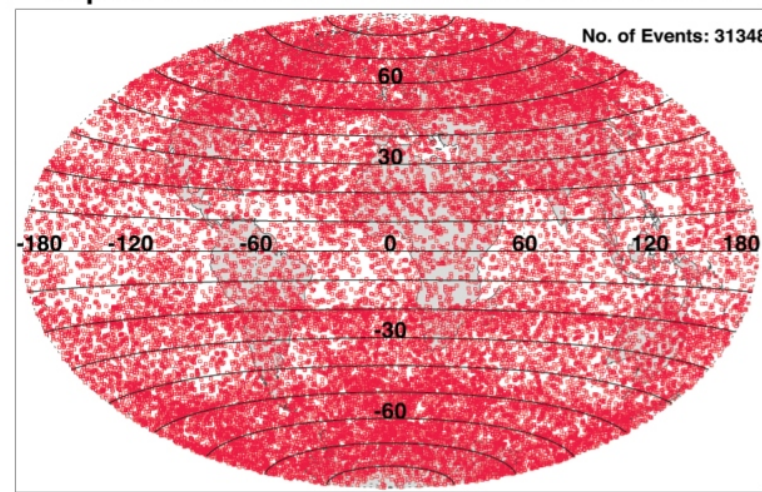

(c) Sep 2006: Formosat-3/COSMIC Dry Temperature Sampling Error

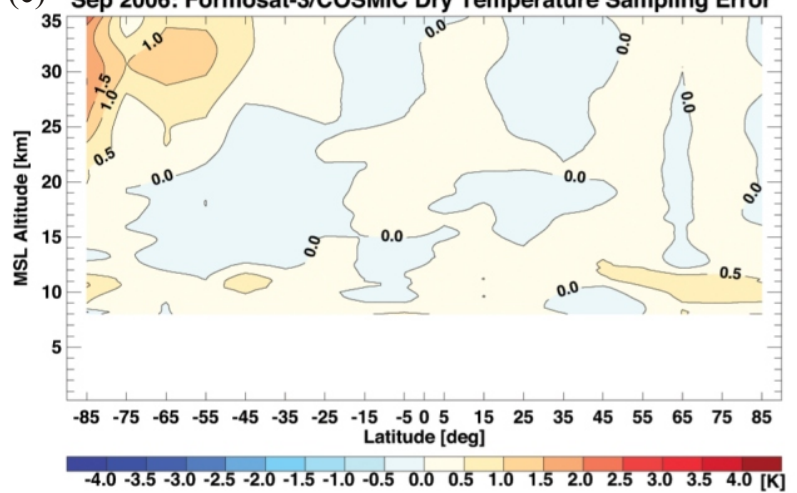

(e) Sep 2006: Systematic Dry Temp Diff ECMWF-Formosat-3/COSMIC

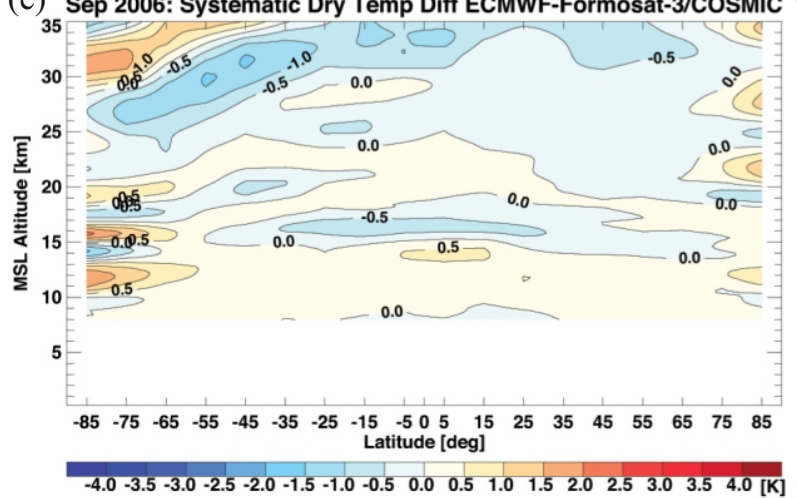

(b)

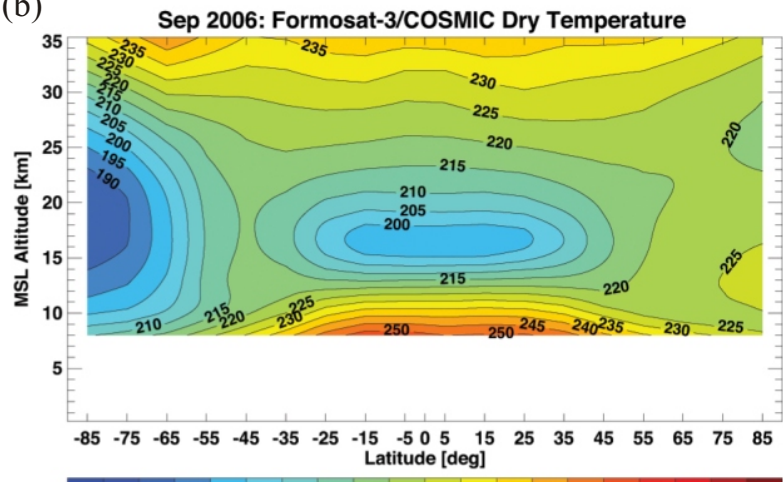

$180185190195200205210215220225230235240245250255260265270[\mathrm{~K}]$

(d) Sep 2006: CHAMP Dry Temperature Sampling Error
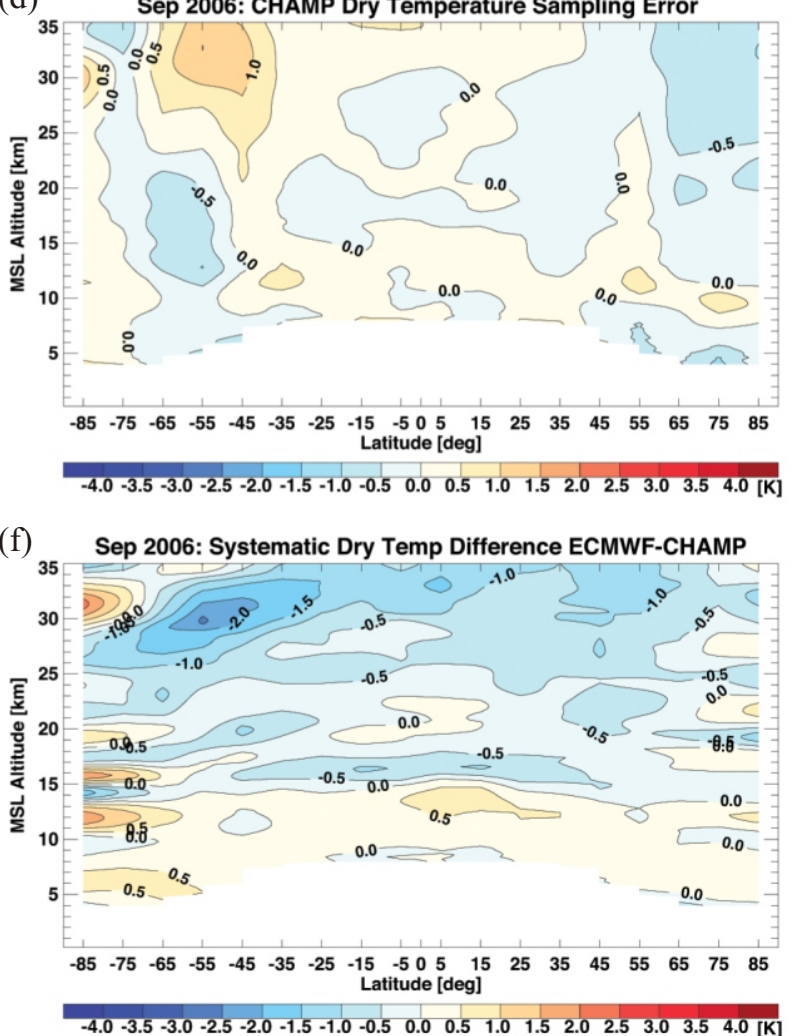

Fig. 1. (a) Distribution of F3C RO events during September 2006 and (b) corresponding dry temperature climatology. Estimated sampling error for (c) F3C and (d) CHAMP and systematic difference of ECMWF to (e) F3C and (f) CHAMP for the same month.

F3C satellites except FM-5 (Flight Model 5) were still close to each other. The sampling is therefore not much different from a single satellite like CHAMP (despite a much higher number of RO profiles). This situation will certainly change with the progressing deployment of the $\mathrm{F} 3 \mathrm{C}$ constellation. The F3C sampling error in the southern polar cap bin is larger than the corresponding sampling error of CHAMP (with a higher orbit inclination of $87^{\circ}$ ). The $\mathrm{F} 3 \mathrm{C}$ sampling error in the northern polar cap bin is less pronounced due to smaller spatial temperature variations during this month (see Fig. 1b). Most F3C measurements during this early stage of the mission were confined to a comparatively small azimuth angle of $40^{\circ}$ (with respect to the orbit plane). The azimuth angle was then opened to $70^{\circ}$; for FM-5 on 9 September 2006, for all other F3C satellites on 11 November 2006, allowing for more $\mathrm{RO}$ events beyond $85^{\circ}$.

The systematic difference of ECWMF to the RO data, based on collocated ECMWF profiles for each RO event, is shown in the bottom panels of Fig. 1 for F3C (Fig. 1e) and CHAMP (Fig. 1f), respectively. The systematic differences are $<0.5 \mathrm{~K}$ in large parts of the domain; the overall features for $\mathrm{F} 3 \mathrm{C}$ and CHAMP are very similar. The wave-like bias structure over Antarctica (and to a lesser extent over the Arctic) is a known deficiency of the ECMWF analyses, 
which is even more pronounced in southern winter months (Gobiet et al. 2005; Foelsche et al. 2006, 2008). Above about $30 \mathrm{~km}$ ECMWF analyses are systematically colder than F3C and CHAMP, but the effect is less pronounced in case of F3C. This feature is typical for ECMWF-CHAMP comparisons from 2001 - 2006 (Foelsche et al. 2008). Validation studies (Gobiet et al. 2007) suggest that these differences are probably caused by an ECMWF cold bias. Overall we note a remarkable consistency of RO climatologies from different satellite missions in the altitude range from 8 to $30 \mathrm{~km}$, even on a monthly basis. In order to more closely investigate this consistency we analyzed seasonal mean fields for different satellites for September-October-November (SON) 2006.

\subsection{Seasonal Climatologies}

Here we focus on the consistency of seasonal climatologies derived from the RO data of four different satellites: CHAMP, FM-1 (Flight Model 1 of the F3C constellation), FM-3, and FM-5. During SON 2006, FM-5 was already in the final orbit, whilst FM-1 and FM-3 where still in the parking orbit, relatively close to each other and therefore sampling similar (although not exactly the same) regions of the atmosphere. The number of atmospheric profiles involved in the climatologies is 12330, 20313, 20061, and 22094 for CHAMP, FM-1, FM-3, and FM-5, respectively (F3C satellites measure setting and rising RO events, CHAMP only setting events).

Figure 2 (top panels) shows the difference between
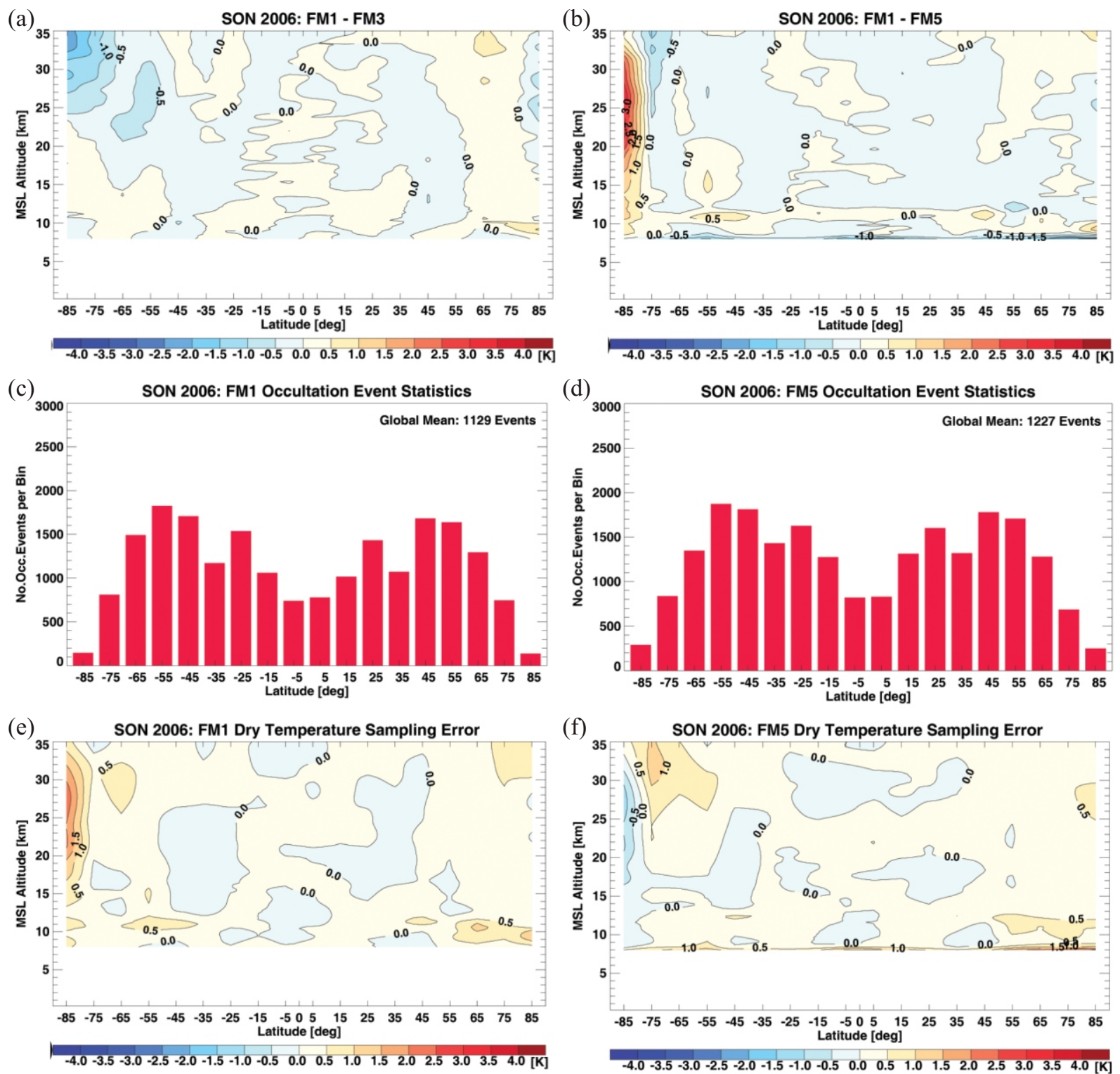

Fig. 2. Systematic difference between SON 2006 zonal mean climatologies derived from different F3C satellites (top panels): (a) FM-1 minus FM-3, (b) FM-1 minus FM-5 are shown. RO events per 10 latitude bin for (c) FM-1 and (d) FM-5. The estimated sampling error for (e) FM-1 and (f) FM-5. 
SON 2006 zonal mean climatologies derived from FM-1 and FM-3 RO data (Fig. 2a) and from FM-1 and FM-5 data (Fig. 2b). The overall agreement is very good but the effect of sampling errors at high latitudes (bottom panels) is clearly visible (see also section 3.1). These sampling errors are relatively large during SON 2006 due to the low orbit altitudes of the F3C satellites (except FM-5) in connection with the orbit inclinations of $72^{\circ}$ and a comparatively small azimuth angle within which $\mathrm{RO}$ events have been received in this early stage of the F3C mission (except FM-5, see section 3.1). An RO event in a polar cap bin is only recorded by an F3C satellite when the transmitting GPS satellite is in the opposite hemisphere. This situation is more easily achieved for FM-5 than for the other F3C satellites. As a consequence, the number of $\mathrm{RO}$ events in the southernmost bin during SON 2006 is almost 300 for FM-5 (Fig. 2c), about 250 for CHAMP (with setting events only but an orbit inclination of $87^{\circ}$ ), but less than 150 for FM-1 (Fig. 2d) and FM-3, respectively. The estimated sampling error for FM-3 (not shown) is qualitatively very similar to that of FM-1 (Fig. 2e) but southern polar cap values are even larger, exceeding $+3 \mathrm{~K}$. The southern polar cap sampling error for FM-5 is considerably smaller (Fig. 2f); the large systematic difference between FM-1 and FM-5 (Fig. 2b) in this bin is thus mainly caused by FM-1 sampling errors.
Since we focus here on data consistency and not on sampling errors, we subtracted the estimated sampling errors (see section 2.2) from the respective climatologies and display the results in Fig. 3. These "double-difference" plots therefore contain systematic differences between the profile data derived from the different satellites as well as any uncertainties in the estimation of the respective sampling errors for both satellites (but not potential common systematic errors).

Systematic differences are $<0.5 \mathrm{~K}$ almost everywhere between 8 and $30 \mathrm{~km}$ altitude, for every satellite combination. In Fig. 3 we kept a contour spacing of $0.5 \mathrm{~K}$ to highlight the systematic features. FM-5 results are on average slightly cooler than CHAMP (0.26 K over the entire domain). Systematic differences of more than $0.5 \mathrm{~K}$ occur mainly above $30 \mathrm{~km}$; a similar situation is encountered for all other F3C CHAMP combinations (not shown). The reason for the systematic difference as seen in Fig. 3a (CHAMP being warmer than $\mathrm{F} 3 \mathrm{C}$ ) is currently under investigation in order to obtain a clear understanding.

Differences between FM-1 and FM-5 (Fig. 3b), FM-1 and FM-3 (Fig. 3c), and FM-3 and FM-5 (Fig. 3d) do not show any systematic features at this resolution, justifying a closer inspection as illustrated in Fig. 4. The mean values for the fields shown in Figs. $3 \mathrm{~b}-\mathrm{d}$ are $-0.033,-0.015$, and $-0.018 \mathrm{~K}$, respectively.
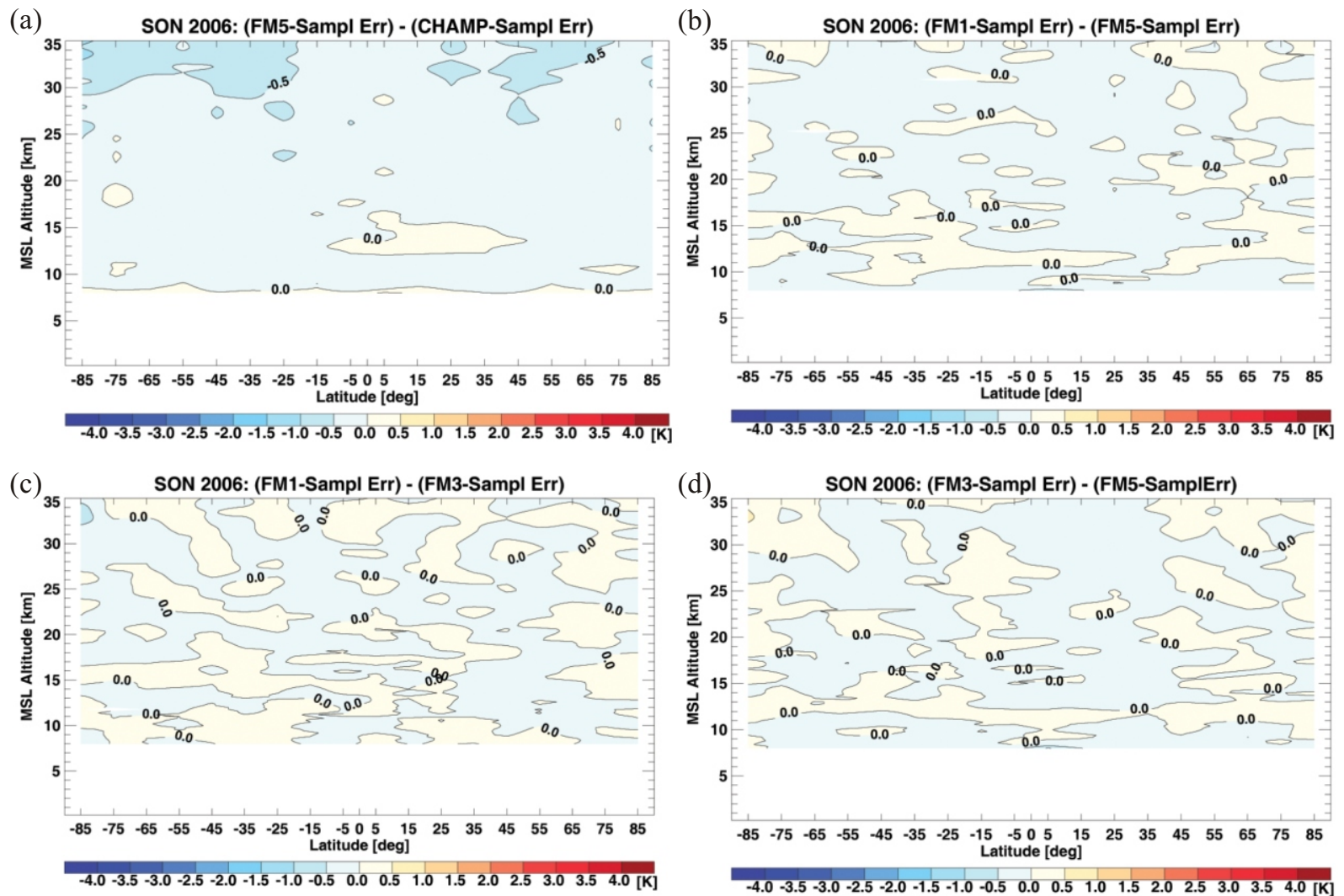

Fig. 3. Systematic differences between SON 2006 zonal mean climatologies for different satellite combinations with the estimated sampling errors subtracted: (a) FM-5 minus CHAMP, (b) FM-1 minus FM-5, (c) FM-1 minus FM-3, and (d) FM-3 minus FM-5 are shown. 

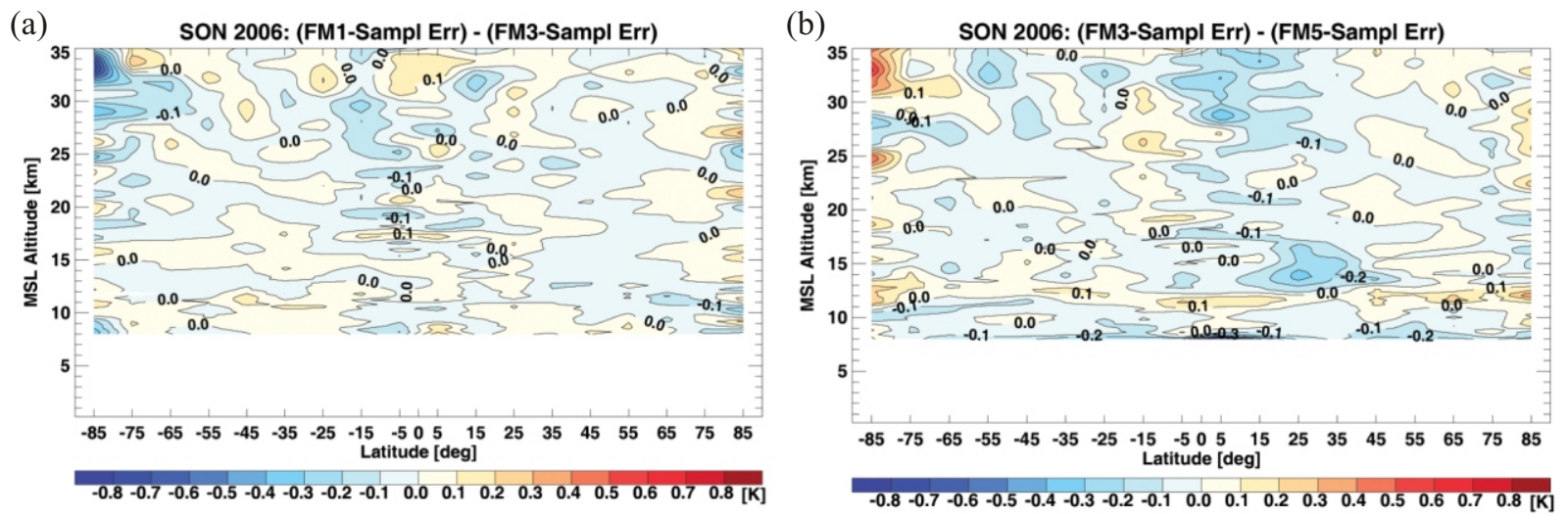

Fig. 4. Systematic differences between SON 2006 zonal mean climatologies from F3C (a) FM-1 and FM-3 and (b) FM-3 and FM-5 with the estimated sampling errors subtracted $(0.1 \mathrm{~K}$ contour spacing).

Figure 4 shows the differences between SON 2006 climatologies derived from FM-1 and FM-3 RO data (Fig. 4a) and FM-3 and FM-5 data (Fig. 4b) with a very fine resolution of $0.1 \mathrm{~K}$ contour spacing. The respective sampling error estimates are again subtracted. It can be seen that the differences are indeed $<0.1 \mathrm{~K}$ almost everywhere. Differences between FM-1 and FM-5 data (not shown) are even slightly smaller than those for FM-3 and FM-5 data (note that FM-1 and FM-3 events are continuously sampled in different regions and at different local times than FM-5 events). The tendency for slightly larger differences in the two polar bins is probably related to remaining errors in the estimation of the sampling errors which are largest in these bins, reaching $3 \mathrm{~K}$ and more for the individual F3C satellites. The results suggest also that the quantitative uncertainty of the sampling error estimation based on ECMWF fields is no more than the order of $10 \%$. We note that these results are based on a preliminary version of our $\mathrm{F} 3 \mathrm{C}$ retrieval, nevertheless the consistency of the climatologies from different satellites is remarkable. It will be interesting to look at systematic differences again when all six F3C satellites will have reached their final orbits.

\subsection{Tropical Tropopause Parameters}

The tropopause as the boundary region between the convectively mixed troposphere and the stably stratified stratosphere is an important domain of the atmospheric system. Tropopause parameters are expected to be valuable indicators for climate change (e.g., Sausen and Santer 2003). RO data with their high vertical resolution are well suited for the determination of tropopause parameters. Previous studies used RO data from GPS/Met (Nishida et al. 2000; Randel et al. 2003), CHAMP (Schmidt et al. 2004; Borsche et al. 2007) and CHAMP + SAC-C (Schmidt et al. 2006).

We calculate tropopause temperature and altitude using the WMO definition of the lapse rate tropopause (LRTP) (World Meteorological Organization 1957). The cold point tropopause (CPTP) temperature and the respective altitude are determined as the coldest temperature above the LRTP. The LRTP and CPTP temperatures and altitudes are calculated for each RO profile and each co-located ECMWF analysis profile. Publicly available NCEP (US National Centers for Environmental Prediction) reanalysis profiles have a too coarse vertical resolution for a fair comparison, but LRTP temperatures are provided by NCEP as a separate product which is thus shown as well.

In an earlier study (Borsche et al. 2007), we focused on seasonal mean tropical tropopause temperatures and altitudes derived from five years of CHAMP data. As main results we found that NCEP reanalysis LRTP temperatures exhibited warm deviations of about $4 \mathrm{~K}$ compared to CHAMP until the end of 2004, decreasing to about $2 \mathrm{~K}$ from 2005 onwards. ECMWF LRTP temperatures were systematically colder than CHAMP by $\sim 2 \mathrm{~K}$ but converged to CHAMP values after February 2006, when a major improvement of the ECMWF model system became effective. On 1 February 2006, the vertical resolution of ECMWF analyses increased from 60 to 91 levels, the horizontal resolution from T511 (spectral representation with triangular truncation at wave number 511) to T799, allowing more smaller-scale atmospheric variability to be represented.

Here we show the temporal evolution of LRTP temperature (Fig. 5a) and LRTP altitude (Fig. 5b) in the Tropics $\left(15^{\circ} \mathrm{S}-15^{\circ} \mathrm{N}\right)$ on a monthly-mean basis until December 2006 and add results from other RO missions. The systematic deviations between CHAMP (black), NCEP (green), and ECMWF (yellow) LRTP temperatures are clearly visible in Fig. 5a as mentioned above. From February 2006 onwards, CHAMP and ECMWF data agree very well. "Error bars" for every third month represent the dispersion of the LRTP temperatures (and altitudes in Fig. 5b) of individual profiles (one standard deviation). RO data from SAC-C (Satélite de Aplicaciones Científicas-C, Hajj et al. 2004) and GRACE (Gravity Recovery and Climate Experi- 
(a) Lapse Rate Tropopause Temperature (Tropics)

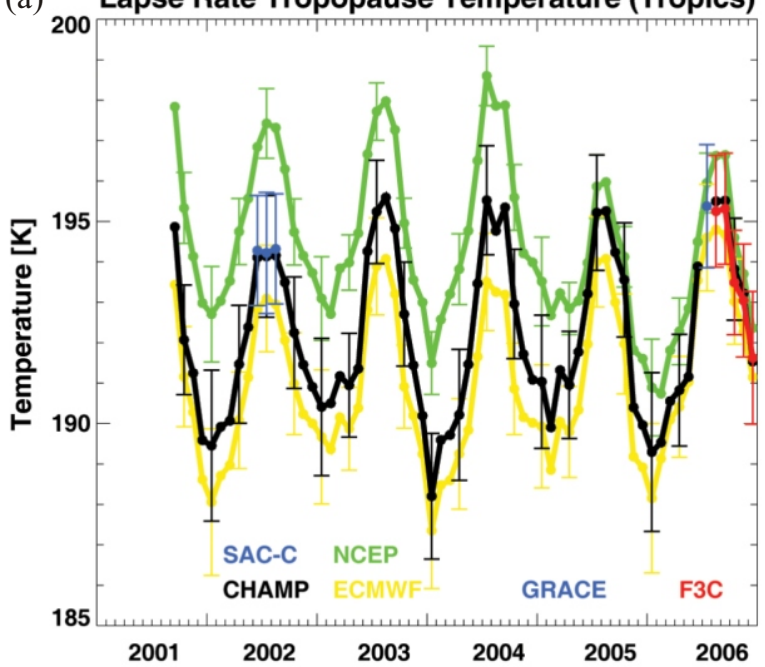

(c)

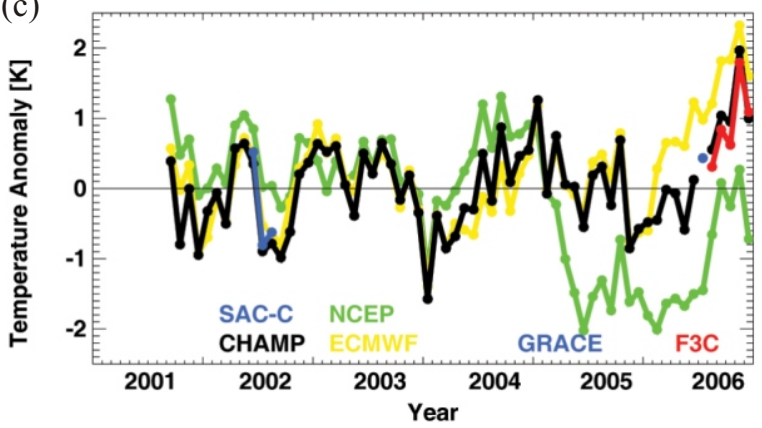

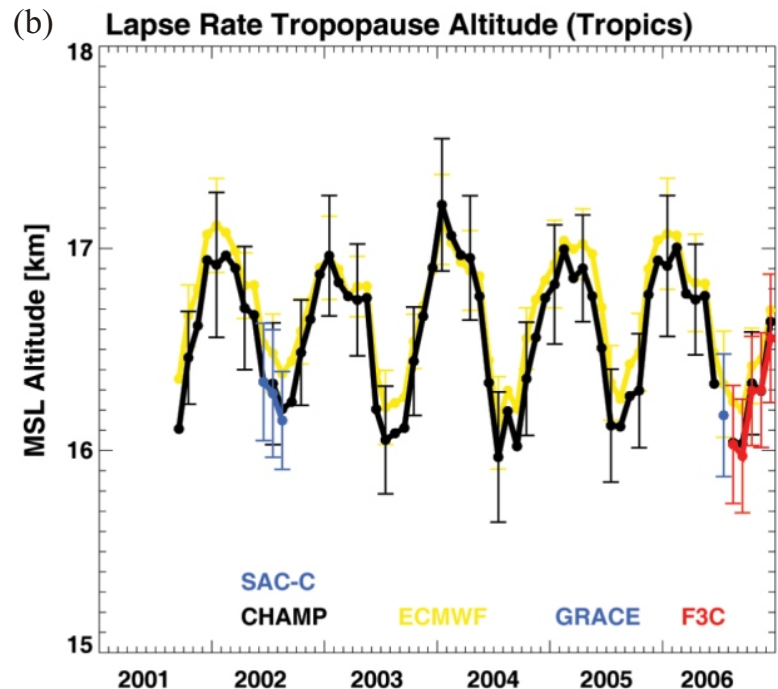

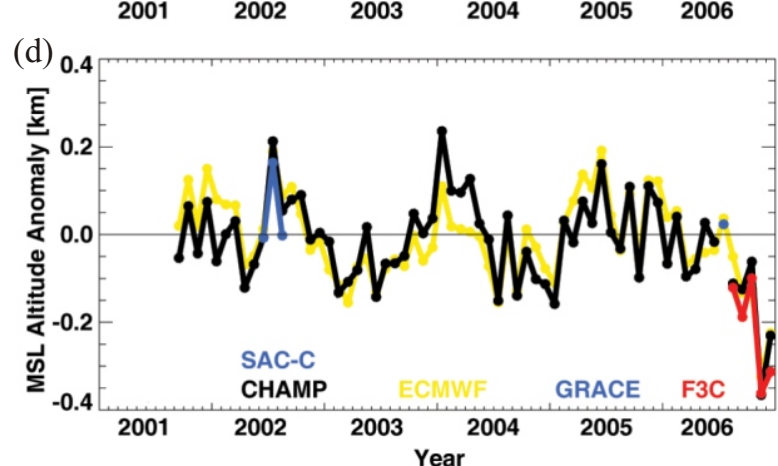

Fig. 5. (a) Temporal evolution of monthly mean tropical LRTP temperature for CHAMP data (black), ECMWF analyses (yellow), NCEP reanalyses (green), and F3C data (red). (b) LRTP altitude for CHAMP data (black), ECMWF data (yellow), and F3C data (red). "Anchor point" months from SAC-C and GRACE are marked in blue. Lower panels: (c) temperature and (d) altitude anomalies for the data shown in panels (a) and (b).

ment, Wickert et al. 2005) have been available for individual months (blue).

The SAC-C results for June, July, and August 2002 and GRACE results (July 2006, filling a "gap" of CHAMP data) serve as "anchor points" and show excellent agreement with CHAMP. This also holds true for LRTP temperatures derived from $\mathrm{F} 3 \mathrm{C}$ data (red, mean values for all 6 satellites), which are added from August 2006 onwards. Comparison amongst F3C FMs is discussed further below. LRTP altitude estimates, which are not available for NCEP data (Fig. 5b), show a very good overall agreement between all systems considered.

The lower panels of Fig. 5 show the corresponding anomalies of LRTP temperature (Fig. 5c) and altitudes (Fig. 5d), in order to highlight intra-seasonal and inter-annual variability and to enable a closer look on similarities and differences. For this purpose, reference monthly means over 2002 - 2005 were computed and subtracted from the absolute monthly mean data, providing anomaly time series cleared from the mean seasonal cycle. In case of RO data, we subtracted CHAMP monthly mean values from all datasets, i.e., also SAC-C, GRACE, and F3C anomalies were referred to the CHAMP mean. The other datasets were each referred to their own 2002 - 2005 means. We did not use 2002 - 2006 for computing the mean, but restricted ourselves to 2002 2005, because of the inhomogeneity of ECMWF data by February 2006 discussed above; the same approach was followed by Steiner et al. (2007), who evaluated RO-derived MSU anomaly time series over the same time period.

In the anomaly space, the systematic tropopause temperature changes in NCEP data in 2005 and in ECMWF data in early 2006 are clearly visible, though overall there is very good agreement in both intra-seasonal and inter-annual variability, in particular between CHAMP and ECWMF. The LRTP anomaly data from the different RO satellites agree within $\sim 0.1-0.3 \mathrm{~K}$ and $\sim 50 \mathrm{~m}$, respectively, which is consistent with the sampling error of single RO satellites (Pirscher et al. 2007). This close matching of independent LRTP data from different RO satellites in very different orbits, obtained without a need for a fine tuning of the WegCenter's OPSv5.2 processing system developed for CHAMP, indicates remarkable consistency and homogeneity of the RO data. Steiner et al. (2007) found similar inter-satellite consistency for RO-derived MSU TLS anomalies in the tropics. 
Tropical CPTP temperatures and altitudes are shown in Fig. 6. General features like the opposite seasonal cycle behavior of tropical tropopause temperatures and altitudes are clearly visible in Figs. 6a - b (as also in LRTP). CPTP altitudes (Fig. 6b) are always higher than LRTP altitudes (Fig. 5b), on average by about $500 \mathrm{~m}$. ECMWF-based mean CPTP temperatures are slightly cooler than RO-based mean values until February 2006, but differences are smaller than corresponding LRTP temperature differences (Fig. 5a). Mean CPTP altitudes based on RO profiles are slightly higher than those based on ECMWF profiles most of the time, for LRTP temperatures the situation is reversed.

The lower panels of Fig. 6 show the anomalies of CPTP temperature (Fig. 6c) and altitude (Fig. 6d), computed in the same way as those for Fig. 5. The small systematic offset between CHAMP and $\mathrm{F} 3 \mathrm{C}$ data in the CPTP temperature anomalies reflects the systematic temperature difference between those data sets (discussed related to Fig. 3a). The available evidence indicates that this difference is approximately time-constant but, as noted in section 3.2, it is currently being investigated to obtain a clear understanding. СРTP temperature, as a more sensitive indicator of poten- tial residual inter-satellite differences than LRTP temperature, is one very useful parameter to help this next level of scrutiny.

Overall, Figs. 5 and 6 show that the agreement of ECMWF and RO data is excellent since February 2006 (see upper panels: Figs. 5a, b, 6a, b; the apparent temperature offset in anomaly space since February 2006, Figs. 5c, 6c, does only reflect the offset of the ECMWF data until January 2006, since the anomaly data refer to $2002-2005$ means). Thus a more detailed quantitative look into the $2^{\text {nd }}$ half of 2006, where both CHAMP and F3C data are available, is worthwhile in order to more closely inspect the level of agreement at the sub-Kelvin and sub- $100 \mathrm{~m}$ scales.

Figure 7 shows details of the evolution of tropical LRTP parameters from July to December 2006. NCEP data are omitted in Fig. 7a since they are out of the plotting range most of the time. In July 2006 there are only GRACE RO data available, mean values for the $\mathrm{F} 3 \mathrm{C}$ constellation (dark red) and data from the six individual $\mathrm{F} 3 \mathrm{C}$ satellites (orange) are shown from August to December.

Figure 8 shows the same for CPTP parameters (note the different altitude range between Figs. $7 \mathrm{~b}$ and $8 \mathrm{~b}$ ). Monthly mean LRTP temperatures from CHAMP and F3C (the mean

(a) Cold Point Tropopause Temperature (Tropics)

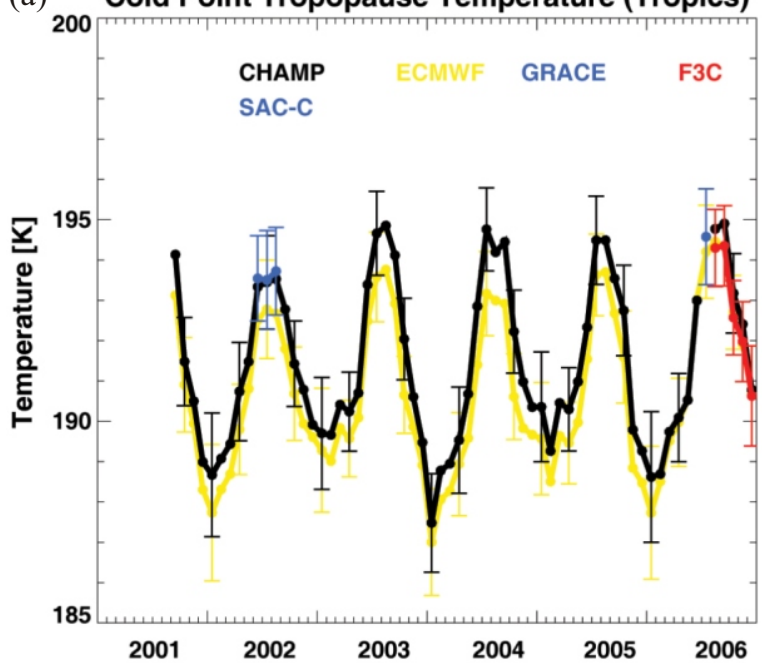

(b) Cold Point Tropopause Altitude (Tropics)

(c)
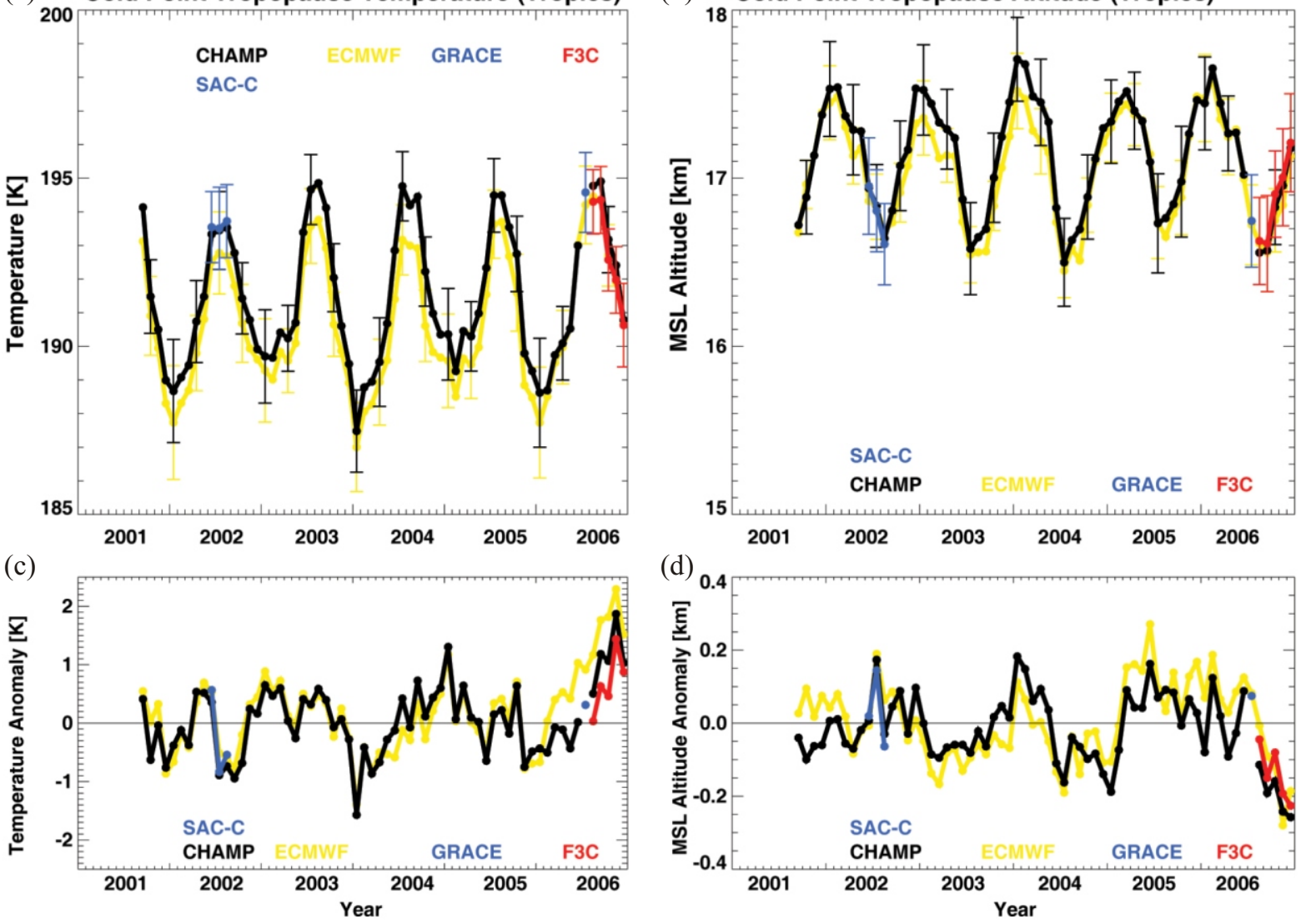

Fig. 6. Temporal evolution of monthly mean tropical CPTP (a) temperature and (b) altitude for CHAMP data (black), ECMWF analyses (yellow), and F3C data (red). "Anchor point" months from SAC-C and GRACE are marked with blue dots. Lower panels: (c) temperature and (d) altitude anomalies for the data shown in panels (a) and (b). 

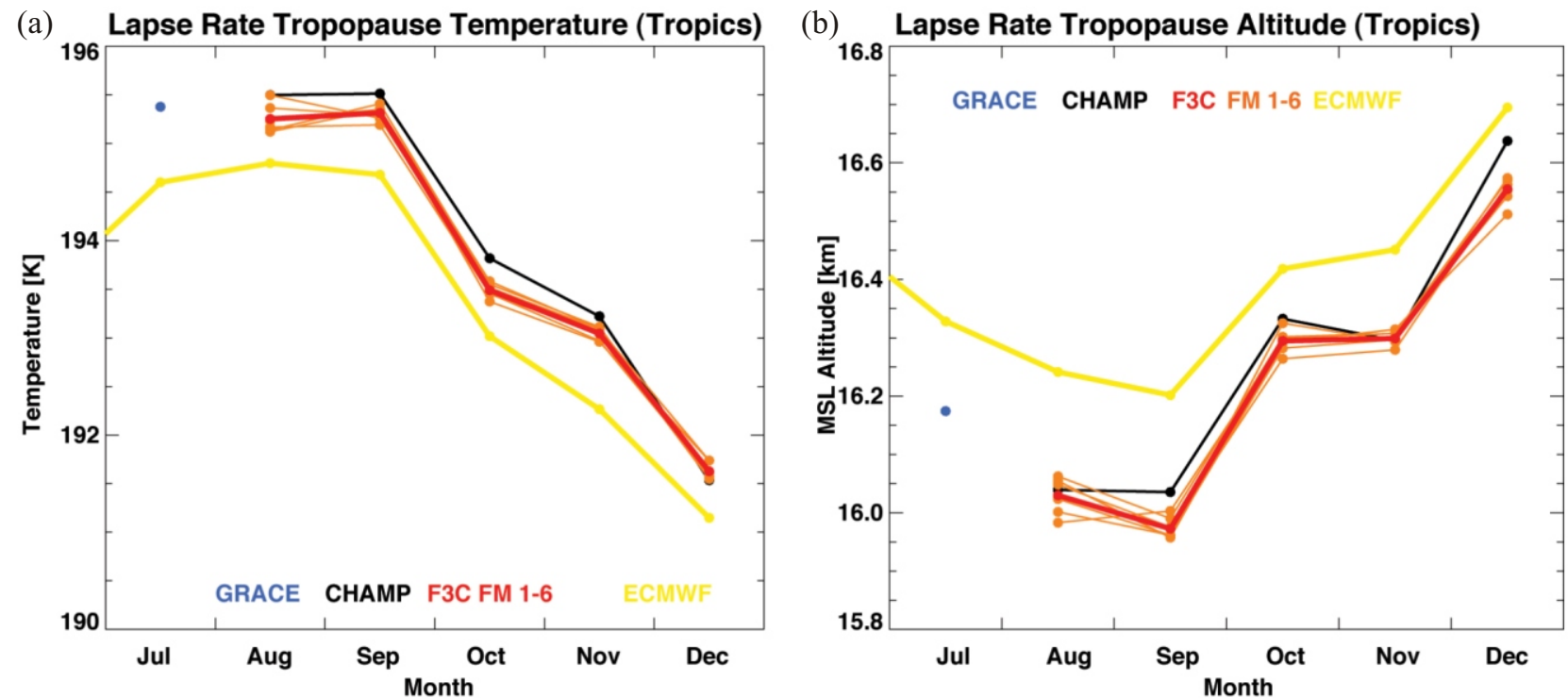

Fig. 7. Temporal evolution of July - December 2006 monthly mean tropical LRTP (a) temperature and (b) altitude for CHAMP data (black), ECMWF analyses (yellow), F3C data (red, mean values), individual F3C satellites (orange), and an "anchor point" month from GRACE (blue).
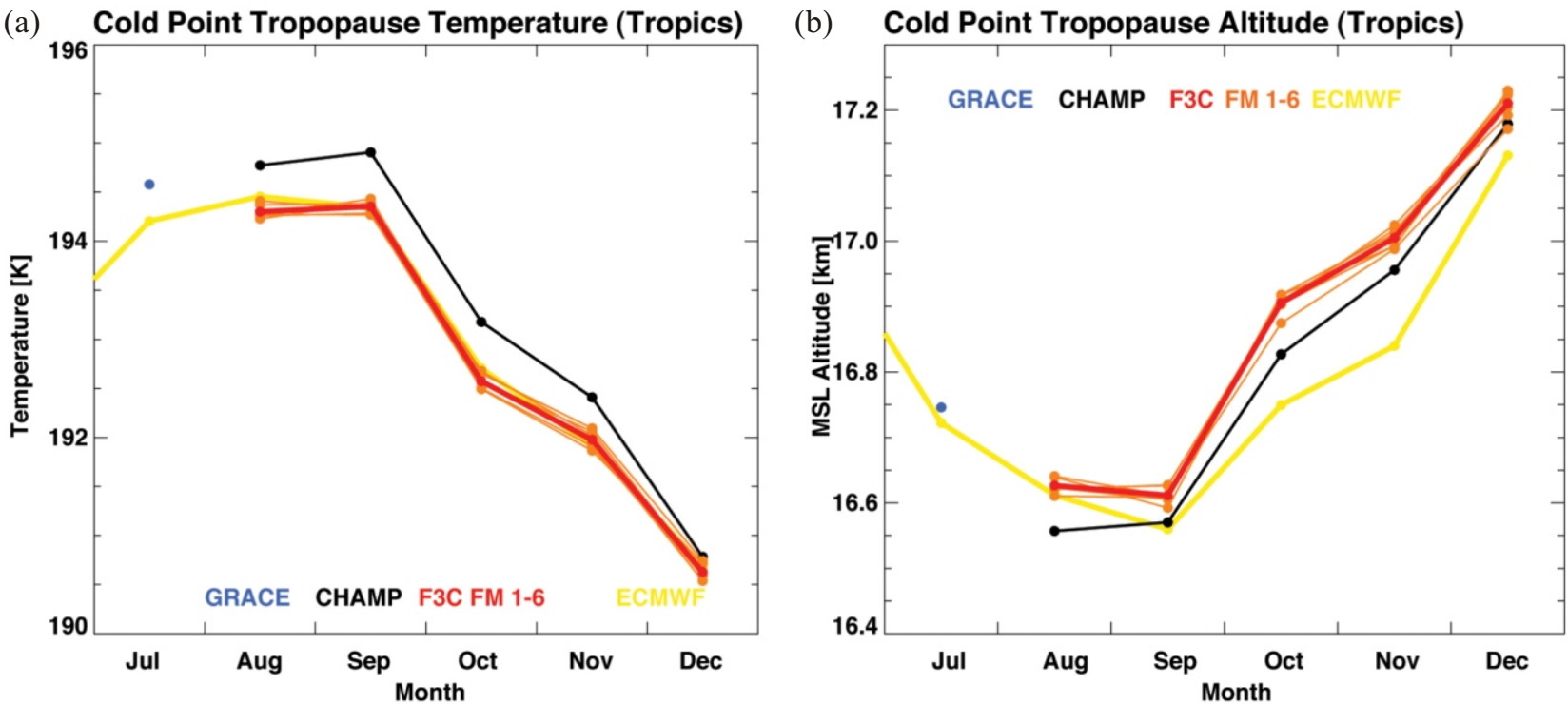

Fig. 8. Temporal evolution of July - December 2006 monthly mean tropical CPTP (a) temperature and (b) altitude for CHAMP data (black), ECMWF analyses (yellow), F3C data (red, mean values), individual F3C satellites (orange), and an "anchor point" month from GRACE (blue).

value for the constellation) agree within 0.2 to $<0.5 \mathrm{~K}$, the LRTP altitudes within 50 to $<100 \mathrm{~m}$; the respective GRACE anchor points are very plausible as well. LRTP temperatures from all six individual $\mathrm{F} 3 \mathrm{C}$ satellites agree within $0.2 \mathrm{~K}$ from September onwards, the spread of the LRTP altitudes estimates from the different $\mathrm{F} 3 \mathrm{C}$ satellites is 50 to $100 \mathrm{~m}$. There are still small systematic differences between ECMWF and the bulk of RO-based estimates, but $<0.5 \mathrm{~K}$ and generally $<100 \mathrm{~m}$, respectively, which are difficult to interpret given the different altitude resolution of RO profiles and ECMWF analyses (with the latter still somewhat coarser). These LRTP results are further supported by the CPTP data presented in Fig. 8.

An interesting feature is that $\mathrm{F} 3 \mathrm{C}$ and ECMWF CPTP temperatures agree very well while CHAMP (and GRACE) values are generally warmer by $\sim 0.5 \mathrm{~K}$ (except in December 2006). LRTP altitudes, on the other hand, show a better agreement between ECMWF and CHAMP (+ GRACE) than between ECMWF and F3C. While differences in details will receive further investigation we conclude overall (as in sec- 
tion 3.2) that there exists a remarkable consistency of data from different $\mathrm{RO}$ satellites.

\subsection{Local Time Sampling}

Given the very good agreement between climatologies derived from different RO satellite data (section 3.1 - 3.3) it is interesting to closely investigate sampling errors since their relative importance increases when the data quality is high, i.e., when observational errors are small. In this climatological context, systematic sampling errors are particularly important. The systematic undersampling of $\mathrm{F} 3 \mathrm{C}$ at polar-cap latitudes beyond $85^{\circ}$ has already been mentioned in section 3.1 and 3.2. Another systematic component in the sampling error can be introduced through uneven local time sampling, resulting in a biased representation of the diurnal cycle (Salby and Callaghan 1997; Leroy 2001; Kirk-Davidoff et al. 2005). Pirscher et al. (2007) investigated this effect for RO climatologies from sun-synchronous and nonsun-synchronous single satellites. Here we extend the analysis to the $\mathrm{F} 3 \mathrm{C}$ mission in its final orbit constellation with $30^{\circ}$ orbit plane separation. For an RO mission with six satellites in orbits with the same inclination and measurements during day and night, this constellation results in a best possible distribution of RO events in local time.

The Earth's oblateness is the main reason for the secular drift of satellite orbit planes. For a circular orbit, the precession rate $\dot{\Omega}\left[\mathrm{rad} \mathrm{s}^{-1}\right]$ with respect to the vernal equinox can be calculated as

$$
\dot{\Omega}=-\frac{3}{2} J_{2}\left(\frac{a_{\mathrm{e}}}{a}\right)^{2} n \cos i
$$

where $J_{2}=1082.63 \cdot 10^{-6}$ is the negative of the second zonal coefficient of spherical harmonics describing the Earth's oblateness, $a_{\mathrm{e}}=6378.137 \mathrm{~km}$ is the mean equator radius of the Earth, $a$ is the semi-major axis of the satellite's orbit, $i$ its inclination, and $n=\sqrt{G M_{\mathrm{e}} / a^{3}}$ is the mean motion of the satellite $\left[\mathrm{rad} \mathrm{s}{ }^{-1}\right.$, where $G=6.67 \cdot 10^{-11} \mathrm{~m}^{3} \mathrm{~kg}^{-1} \mathrm{~s}^{-2}$ is the gravitational constant and $M_{\mathrm{e}}=5.97 \cdot 10^{24} \mathrm{~kg}$ the mass of the Earth (Boain 2005). The precession rate increases with decreasing orbit altitude and with decreasing inclination. For special combinations of $i$ and $a$, the precession rate equals $0.9856^{\circ} /$ day $\left(360^{\circ} / 365.2564\right.$ day), the mean motion of the Earth around the Sun, resulting in a sun-synchronous orbit. For F3C satellites with $i=72^{\circ}$ and an assumed final orbit altitude of $\left(a-a_{\mathrm{e}}\right)$ $=800 \mathrm{~km}$, the precession rate equals $-2.0361 \%$ day. The precession rate with respect to the sun, $\dot{\Omega}_{\mathrm{s}}$, is given by

$$
\dot{\Omega}_{\mathrm{S}}=0.9856^{\circ} / \text { day }-\dot{\Omega}
$$

For a sun-synchronous satellite $\dot{\Omega}_{\mathrm{S}}=0^{\circ}$ /day, whilst for $\mathrm{F} 3 \mathrm{C} \dot{\Omega}_{\mathrm{S}}=3.0217^{\circ} /$ day (or $180^{\circ}$ in about 60 days). Figure 9

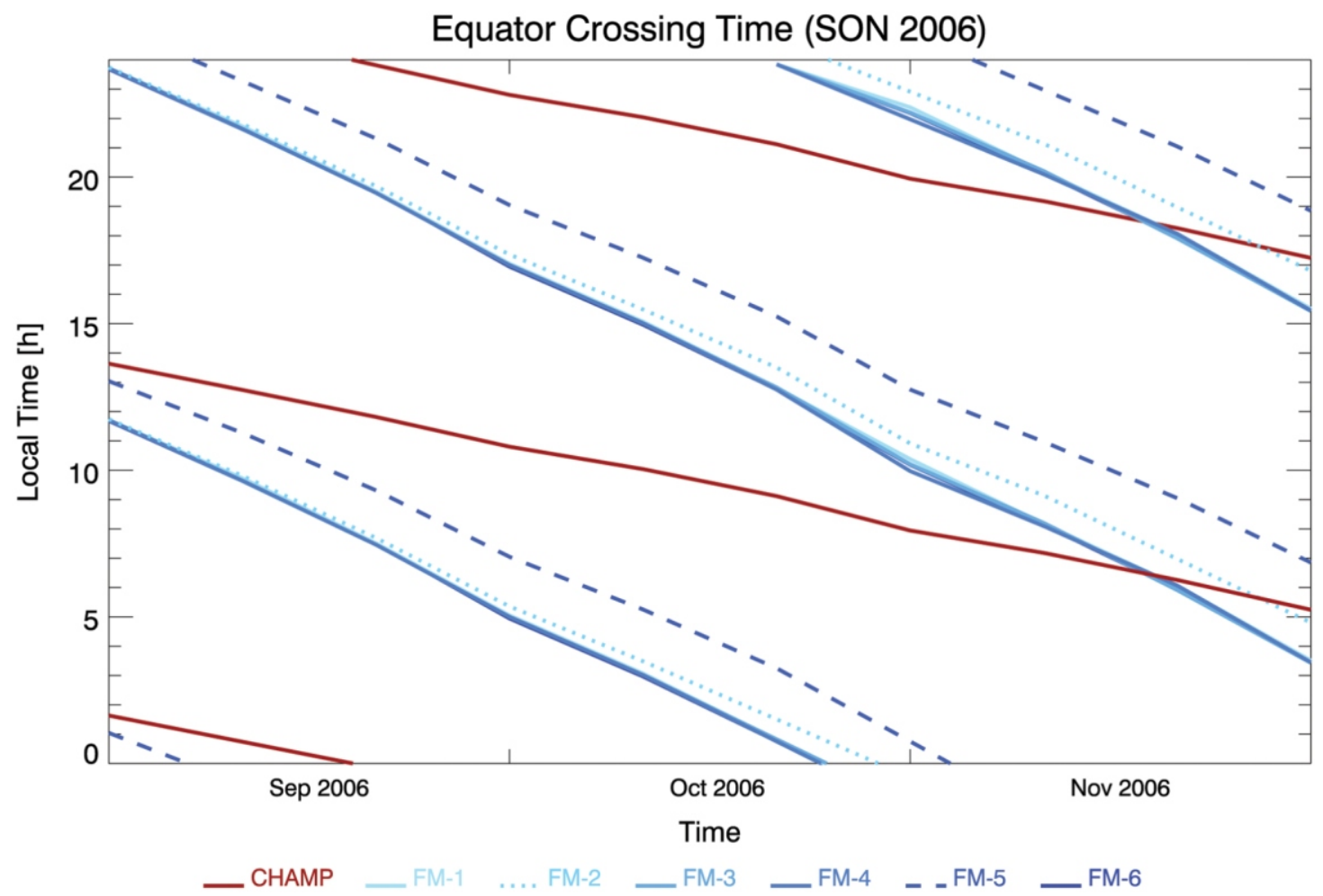

Fig. 9. Local time of equatorial crossing for CHAMP (dark red) and the six F3C satellites (different tones of blue). 
illustrates the local time drift of CHAMP and the six F3C satellites for the period September - November 2006 (based on orbit elements/two-line element sets every 10 days). Even though the orbit altitude of CHAMP ( $360 \mathrm{~km}$ in SON 2006) is lower than that of the $\mathrm{F} 3 \mathrm{C}$ satellites, the local time drift is smaller due to the higher inclination of CHAMP [see Eq. (2)]. The orbit of FM-2 has been raised during this period, leading to a continuously slower drift in local time. FM-5 has already reached its final orbit so that it is separated from the bulk of the other F3C satellites.

RO measurements of a single satellite at the Equator are distributed around two local times, separated by exactly 12 hours. With a precession rate of $\sim 3 \%$ day, the $\mathrm{RO}$ measurements from a single $\mathrm{F} 3 \mathrm{C}$ satellite (in final orbit) thus drift through all local times within $\sim 60$ days, and for the entire F3C constellation (with $30^{\circ}$ orbit plane separation) it takes about 10 days to sample the diurnal cycle.

At higher latitudes, however, the situation is different (cf. Leroy 2001). The crossing times of a single F3C satellite at $60^{\circ} \mathrm{N}$, for example, are separated by only $\sim 7.5$ hours. From about $60^{\circ}$ poleward, it takes more than one month to sample the diurnal cycle with the full F3C constellation.

Figures 10a, c show the suborbital points and the corresponding simulated $\mathrm{RO}$ event locations for the full $\mathrm{F} 3 \mathrm{C}$ constellation over one month as functions of local time and latitude (for simulation setup details, see Pirscher et al. 2007). 2004 - 2005 was the simulation analysis period and the underlying ECMWF fields for the sampling error estimation are from this period. An interesting feature is the clustering of RO profiles in local time. For the particular month shown in Fig. 10, the RO events are concentrated around 6 LT (local time) on the Northern Hemisphere (NH) and around $18 \mathrm{LT}$ in the Southern Hemisphere (SH) (Figs. 10b, d), respectively, although the global distribution of RO events with respect to local time is uniform.

One month later (Fig. 11) the entire constellation has drifted by about 6 hours in local time, resulting in a concentration of RO events around midnight in the $\mathrm{NH}$ and around noon in the SH, respectively, while the LT distribution of RO events at low latitudes stays uniform.

Figure 12a shows the temporal evolution of estimated sampling error of the simulated $\mathrm{F} 3 \mathrm{C}$ constellation at tropical latitudes $\left(20^{\circ} \mathrm{S}-20^{\circ} \mathrm{N}\right)$, based on the four-times-daily ECMWF analysis fields of 2004. The local time component of the sampling error was computed according to Pirscher et al. (2007), and is shown in Fig. 12b. As expected, the local time component is without clear systematic patterns and very small (order $0.01 \mathrm{~K}$ fluctuations only).

The results for mid and high latitudes are shown in Fig. 13. Here, the sampling situation described above leads to an uneven weighting of day and night temperatures, resulting in alternating small positive and negative deviations (half-cycle period $\sim 60$ days) with opposite signs in the local-time component of the sampling error in the $\mathrm{NH}$ and $\mathrm{SH}$, respectively (Figs. 13c, d). For monthly-mean zonal-mean climatologies with $10^{\circ}$ latitudinal resolution, this effect (a)

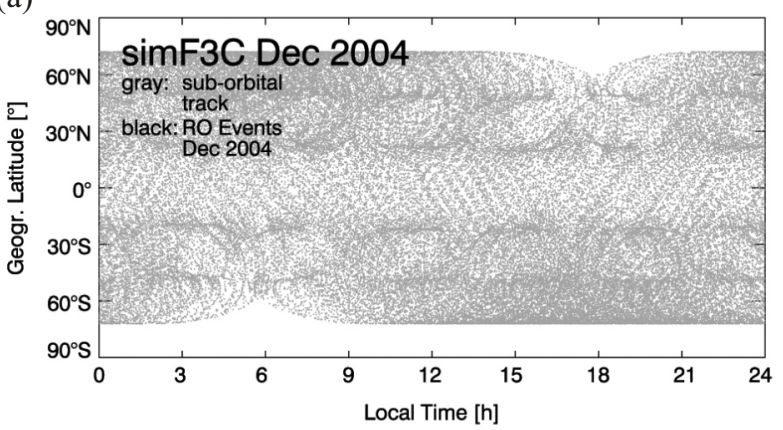

(c)

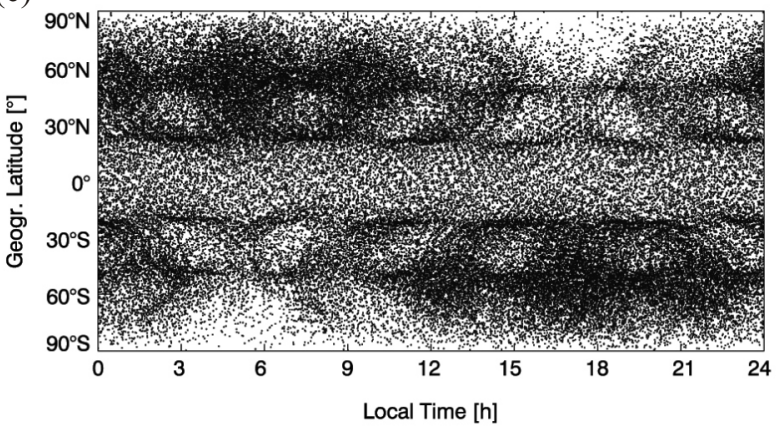

(b)

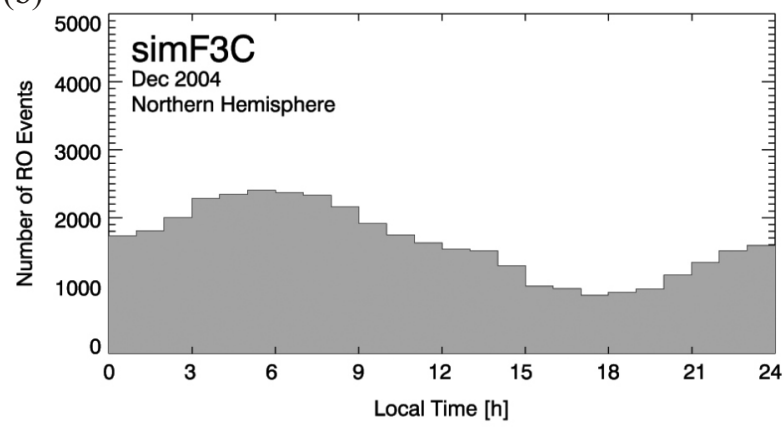

(d)

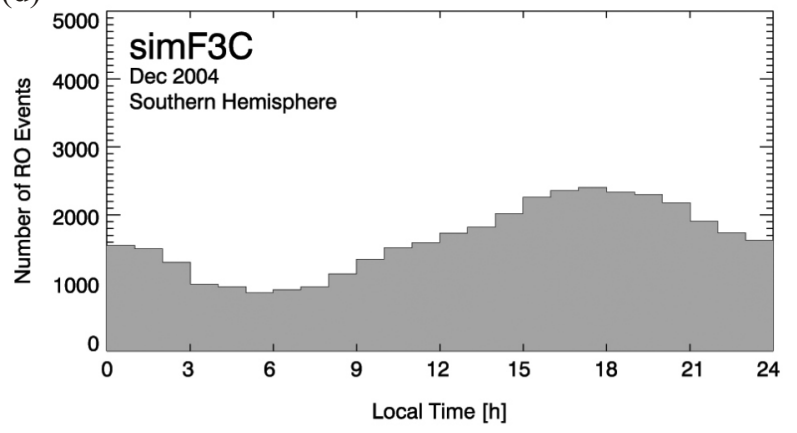

Fig. 10. (a) Simulated F3C orbit track, (c) occultation event locations and number of occultation events with respect to local time separated for both hemispheres [(b) Northern Hemisphere, (d) Southern Hemisphere] in December 2004 (2004 - 2005 was the simulation analysis period). 
amounts to about $\pm 0.03 \mathrm{~K}$. It disappears (to $<0.01 \mathrm{~K}$ ) when mean values over longer time periods (at least seasons) are considered. The full F3C sampling error is generally $<0.1 \mathrm{~K}$ (Figs. 12a, 13a, b) with an exception in the sampling of the extratropical (NHSM, SHSM) tropopause altitude region where errors systematically exceed 0.1 to $0.2 \mathrm{~K}$. The reason is the high space-time temperature variability of this troposphere/stratosphere exchange region which would need even more than six satellites to be sampled to $<0.1 \mathrm{~K}$ error.

We have also performed a similar analysis for the $\mathrm{F} 3 \mathrm{C}$ constellation in the originally planned configuration with $24^{\circ}$ orbit plane separation. Regarding local time sampling, this situ- ation is similar to the loss of one satellite in the final constellation (with $30^{\circ}$ plane separation). The sampling errors (not shown) are only slightly larger, which means that loosing one satellite would not markedly degrade the climate monitoring capability of the $\mathrm{F} 3 \mathrm{C}$ constellation. Additional degradation of the constellation would gradually further increase the sampling error, to ultimately match the single satellite situation analyzed by Pirscher et al. (2007). Practically, when constructing a record of climatologies from a number of satellites varying in time, it is therefore important to quantitatively co-estimate the sampling error, which can be done as described in section 2.2 (see also Pirscher et al. 2007 and Foelsche et al. 2008).
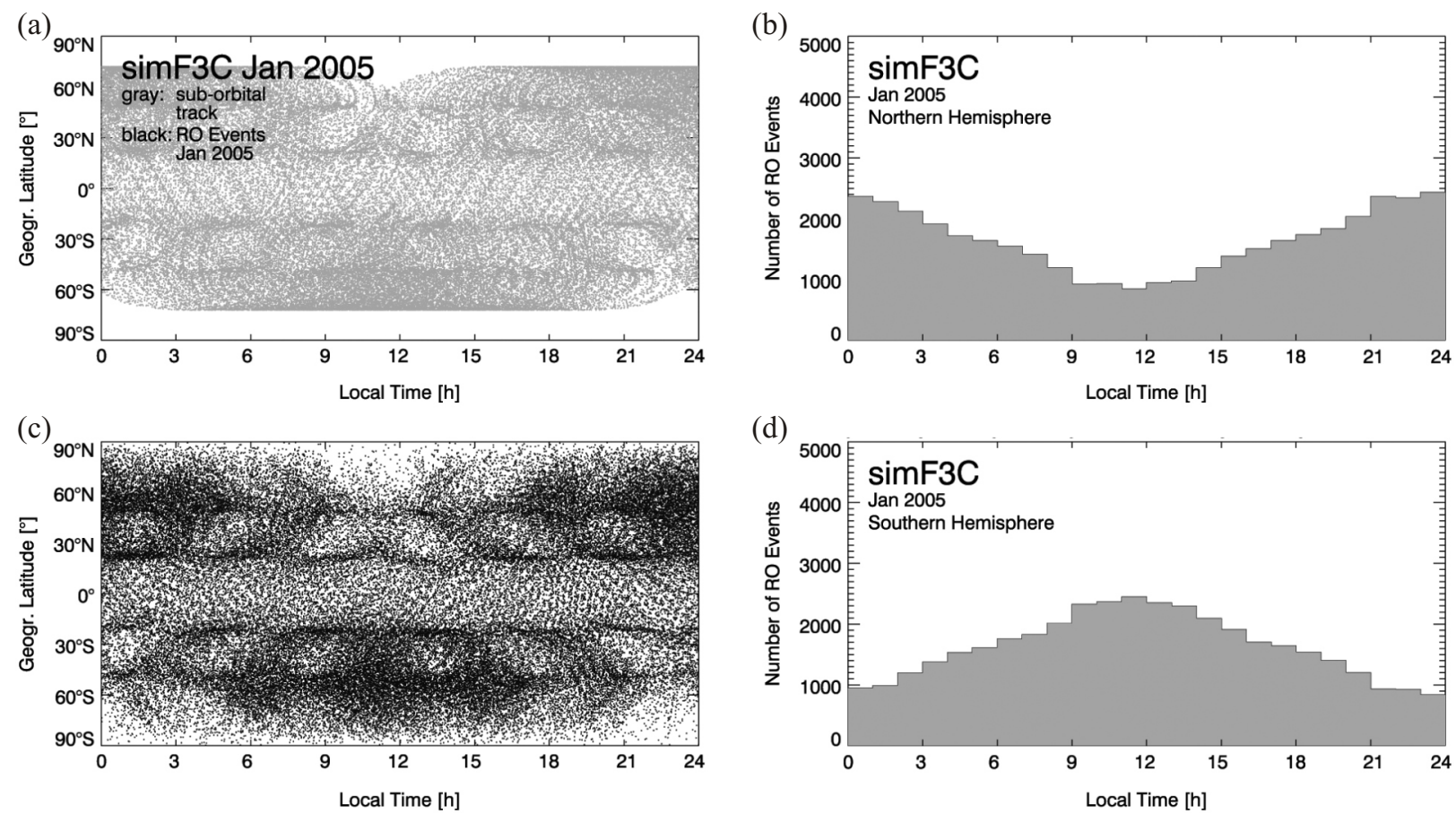

Fig. 11. Same format as Fig. 10 but sampling situation for January 2005, one month later.

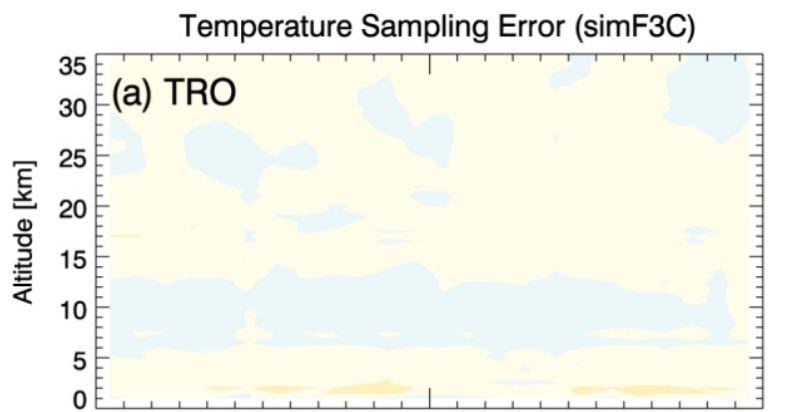

J F M A M J JASONDJFMAM J JASOND Year 2004 Year 2005

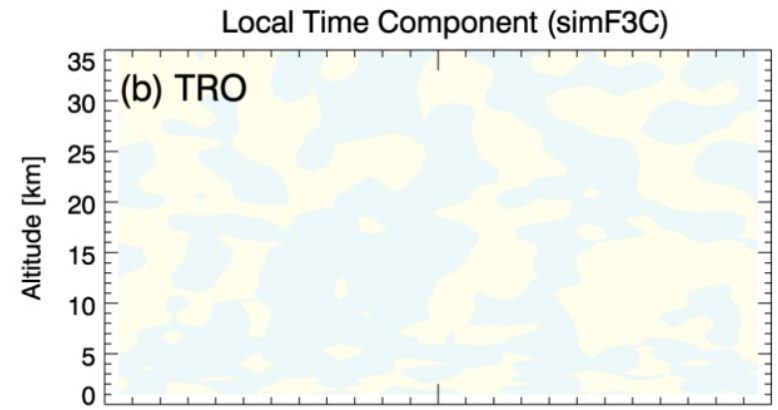

JFMAMJJASONDJFMAMJJASOND

Year $2004 \quad$ Year 2005

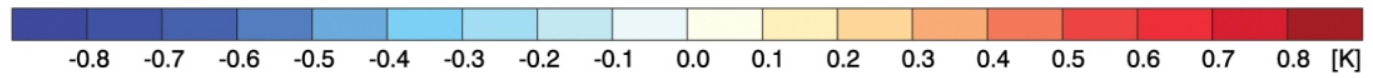

Fig. 12. (a) Time series of the monthly-mean temperature sampling error and (b) its local time component for the full $\mathrm{F} 3 \mathrm{C}$ constellation between $20^{\circ} \mathrm{S}$ and $20^{\circ} \mathrm{N}$. 

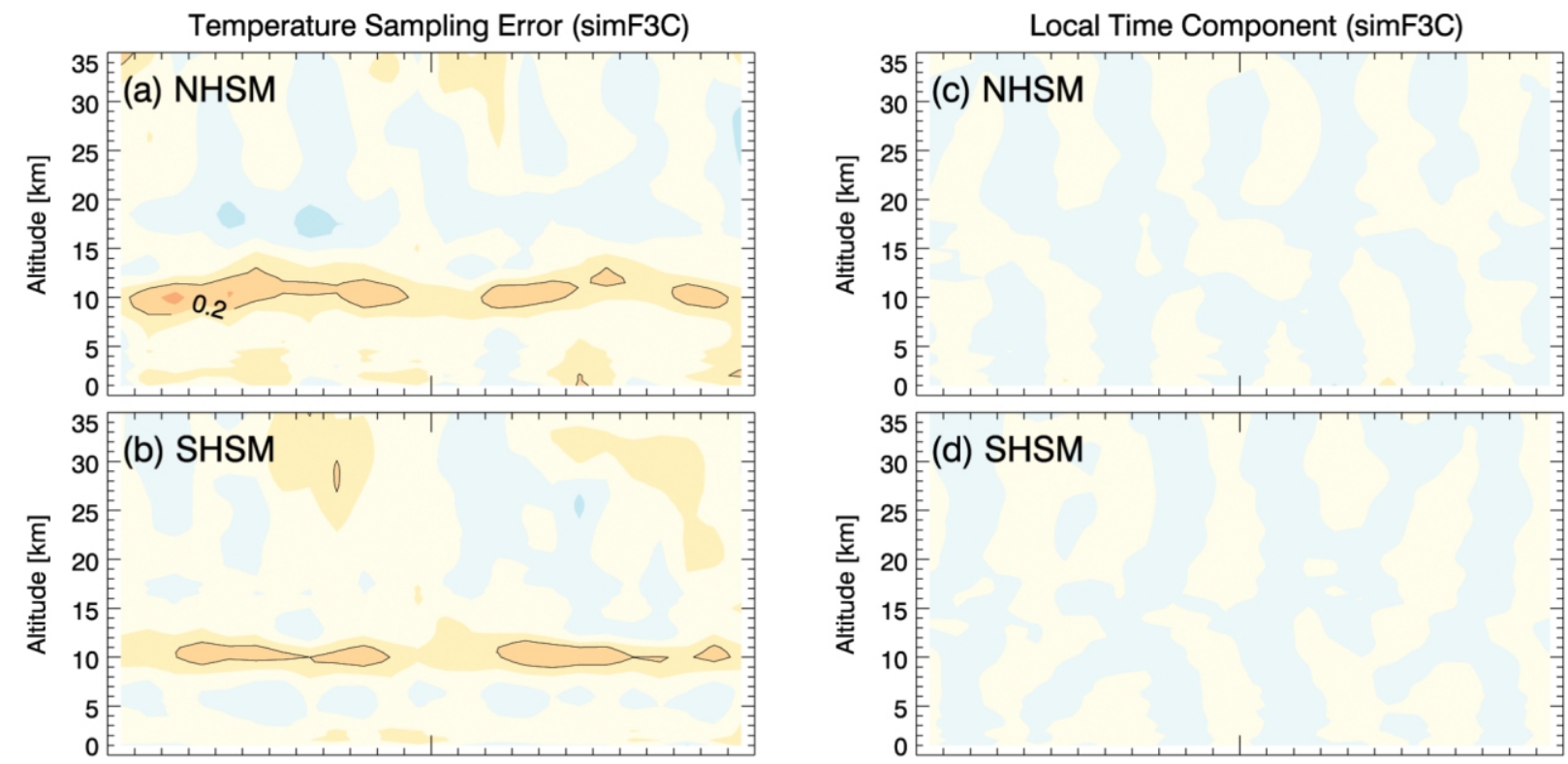

JFMAM J JASONDJFMAM J JASOND Year 2004 Year 2005

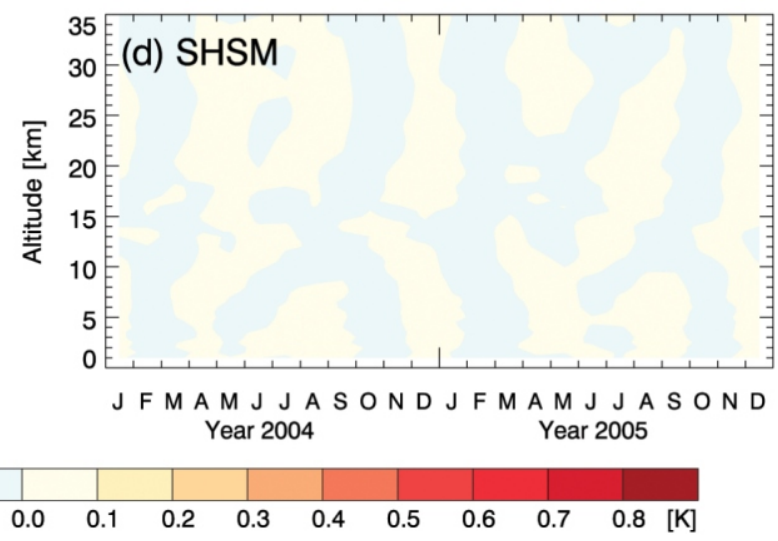

Fig. 13. (a) and (b): Time series of the monthly-mean temperature sampling error and its local time component for the full $\mathrm{F} 3 \mathrm{C}$ constellation for (c) $\mathrm{NH}$ sub-tropics and mid-latitudes $\left(20-60^{\circ} \mathrm{N}\right)$ and (d) SH sub-tropics and mid-latitudes $\left(20-60^{\circ} \mathrm{S}\right)$, respectively.

\section{CONCLUSIONS}

We used radio occultation (RO) data from the recently launched Taiwan/US FORMOSAT-3/COSMIC (F3C) constellation to build zonal mean climatologies. We showed initial results for monthly and seasonal dry temperature climatologies as well as tropical tropopause parameters. Our results indicate excellent agreement between RO climatologies from different $\mathrm{F} 3 \mathrm{C}$ satellites as well as between data from different RO missions (F3C, CHAMP, SAC-C, and GRACE). After subtraction of the estimated respective sampling error, seasonal temperature climatologies derived from different $\mathrm{F} 3 \mathrm{C}$ satellites agree to within $<0.1 \mathrm{~K}$ almost everywhere in the considered domain between 8 and $35 \mathrm{~km}$ altitude.

Tropical lapse rate tropopause parameters (temperature and altitude) derived from F3C, CHAMP, SAC-C, and GRACE show remarkable consistency (generally $<0.2$ $0.5 \mathrm{~K},<50-100 \mathrm{~m}$ agreement) and indicate that data from different RO mission can indeed be combined without need for inter-calibration.

Simulation results for the fully deployed F3C constellation, focusing on sampling error, revealed uneven local time sampling as a small but systematic oscillatory component of the sampling error in monthly mean climatologies in the extratropics (hemispherically anti-symmetric, half cycle $\sim 60$ days, $\pm 0.03 \mathrm{~K}$ amplitude). Simulation studies such as this may also help to design future RO missions with optimal sampling characteristics.

Acknowledgements The Authors would like to acknowledge UCAR (Boulder, CO, USA) for the provision of FORMOSAT-3/COSMIC and SAC-C radio occultation data, GFZ (Potsdam, Germany) for providing CHAMP and GRACE radio occultation data (in particular to T. Schmidt for continuous support), ECMWF (Reading, UK) for access to their global operational analysis data, and NCEP (Camp Springs, MD, USA) for access to their tropopause reanalysis data. The End-to-end Generic Occultation Performance Simulator (EGOPS) software, developed by Wegener Center and Partners based on funds mainly from the European Space Agency (ESA), supported the work and we thank in particular EGOPS technical lead J. Fritzer for continuous support. The work was supported by the Austrian Science Fund (FWF) under research grant P18837N10 (CLIMROCC project).

\section{REFERENCES}

Boain, R. J., 2005: A-B-Cs of Sun-Synchronous Orbit Mission Design. In: Coffey, S. L. and A. J. Treder (Eds.), Spaceflight Mechanics 2004 - Part I, Univelt Inc., 85-104.

Borsche, M., A. Gobiet, A. K. Steiner, U. Foelsche, G. Kirchengast, T. Schmidt, and J. Wickert, 2006: Pre-operational retrieval of radio occultation based climatologies. In: Foelsche, U., G. Kirchengast, and A. Steiner (Eds.), Atmosphere and Climate: Studies by Occultation Methods, 
Springer, Berlin, 315-323, doi: 10.1007/3-540-34121-8 26. [Link]

Borsche, M., G. Kirchengast, and U. Foelsche, 2007: Tropical tropopause climatology as observed with radio occultation measurements from CHAMP compared to ECMWF and NCEP Analyses. Geophys. Res. Lett., 34, L03702, doi: 10.1029/2006GL027918. [Link]

Christy, J. R. and R.W. Spencer, 2005: Correcting temperature data sets. Science, 310, 972-973, doi:10.1126/science.310. 5750.972. [Link]

Foelsche, U., G. Kirchengast, and A. K. Steiner, 2003: Global climate monitoring based on CHAMP/GPS radio occultation data. In: C. Reigber, H. Lühr, and P. Schwintzer (Eds.), First CHAMP Mission Results for Gravity, Magnetic and Atmospheric Studies, Springer, Berlin, 397-407.

Foelsche, U., A. Gobiet, A. Löscher, G. Kirchengast, A. K. Steiner, J. Wickert, and T. Schmidt, 2005: The CHAMPCLIM project: An overview. In: Reigber, C., H. Lühr, P. Schwintzer, and J. Wickert (Eds.), Earth Observation with CHAMP - Results from Three Years in Orbit, Springer, Berlin, 615-620, doi: 10.1007/3-540-26800-6_98. [Link]

Foelsche, U., A. Gobiet, A. K. Steiner, M. Borsche, J. Wickert, T. Schmidt, and G. Kirchengast, 2006: Global climatologies based on radio occultation data: The CHAMPCLIM project. In: Foelsche, U., G. Kirchengast, and A. Steiner (Eds.), Atmosphere and Climate: Studies by Occultation Methods, Springer, Berlin, 303-314, doi: 10.1007/3-54034121-8_25. [Link]

Foelsche, U., M. Borsche, A. K. Steiner, A. Gobiet, B. Pirscher, G. Kirchengast, J. Wickert, and T. Schmidt, 2008: Observing climate change with radio occultation data from the CHAMP satellite. Climate Dyn., 31, 49-65, doi: 10.1007/ s00382-007-0337-7. [Link]

Gobiet, A. and G. Kirchengast, 2004: Advancements of GNSS radio occultation retrieval in the upper stratosphere for optimal climate monitoring utility. J. Geophys. Res., 109, D24110, doi: 10.1029/2004JD005117. [Link]

Gobiet, A., U. Foelsche, A. K. Steiner, M. Borsche, G. Kirchengast, and J. Wickert, 2005: Climatological validation of stratospheric temperatures in ECMWF operational analyses with CHAMP radio occultation data. Geophys. Res. Lett., 32, L12806, doi: 10.1029/2005GL022617. [Link]

Gobiet, A., G. Kirchengast, G. L. Manney, M. Borsche, C. Retscher, and G. Stiller, 2007: Retrieval of temperature profiles from CHAMP for climate monitoring: Intercomparison with Envisat MIPAS and GOMOS and different analyses. Atmos. Chem. Phys., 7, 3519-3536.

Grody, N. C., K. Y. Vinnikov, M. D. Goldberg, J. T. Sullivan, and J. D. Tarpley, 2004: Calibration of multisatellite observations for climatic studies: Microwave Sounding Unit (MSU). J. Geophys. Res., 109, D24104, doi: 10.1029/ 2004JD005079. [Link]

Hajj, G. A., E. R. Kursinski, L. J. Romans, W. I. Bertiger, and S. S. Leroy, 2002: A technical description of atmospheric sounding by GPS occultation. J. Atmos. Sol.-Terr. Phys.,
64, 451-469, doi: 10.1016/S1364-6826(01)00114-6. [Link] Hajj, G. A., C. O. Ao, P. A. Iijima, D. Kuang, E. R. Kursinski, A. J. Mannucci, T. K. Meehan, L. J. Romans, M. de la Torre Juarez, and T. P. Yunck, 2004: CHAMP and SAC-C atmospheric occultation results and intercomparisons. $J$. Geophys. Res., 109, D06109, doi: 10.1029/2003JD003909. [Link]

Healy, S. B, 2001: Smoothing radio occultation bending angles above $40 \mathrm{~km}$. Ann. Geophys., 19, 459-468.

Hedin, A. E, 1991: Extension of the MSIS thermosphere model into the middle and lower atmosphere. J. Geophys. Res., 96, 1159-1172, doi: 10.1029/90JA02125. [Link]

Karl, T. R., S. J. Hassol, C. D. Miller, and W. L. Murray (Eds.), 2006: Temperature trends in the lower atmosphere: Steps for understanding and reconciling differences, A Report by the Climate Change Science Program and the Subcommittee on Global Change Research, Washington, DC.

Kirk-Davidoff, D., R. M. Goody, and J. G. Anderson, 2005: Analysis of sampling errors for climate monitoring satellites. J. Climate, 18, 810-822, doi: 10.1175/JCLI-3301.1. [Link]

Kursinski, E. R., G. A. Hajj, K. R. Hardy, J. T. Schofield, and R. Linfield, 1997: Observing the Earth's atmosphere with radio occultation measurements using the Global Positioning System. J. Geophys. Res., 102, 23429-23465, doi: 10.1029/97JD01569. [Link]

Leroy, S. S., 2001: The effects of orbital precession on remote climate monitoring. J. Climate, 14, 4330-4337, doi: 10. 1175/1520-0442(2001)014<4330:TEOOPO>2.0.CO;2. [Link]

Leroy, S. S., J. A. Dykema, and J. G. Anderson, 2006: Climate benchmarking using GNSS occultation. In: Foelsche, U., G. Kirchengast, and A. Steiner (Eds.), Atmosphere and Climate: Studies by Occultation Methods, Springer, Berlin, 287-302, doi: 10.1007/3-540-34121-8_24. [Link]

Mears, C. A. and F. J. Wentz, 2005: The effect of diurnal correction on satellite-derived lower tropospheric temperature. Science, 309, 1548-1551, doi: 10.1126/science.1114772. [Link]

Nishida, M., A. Shimizu, T. Tsuda, C. Rocken, and R. H. Ware, 2000: Seasonal and longitudinal variations in the tropical tropopause observed with the GPS occultation technique (GPS/MET). J. Meteorol. Soc. Jpn., 78, 691-700.

Pirscher, B., U. Foelsche, B. C. Lackner, and G. Kirchengast, 2007: Local time influence in single-satellite radio occultation climatologies from sun-synchronous and non sunsynchronous satellites. J. Geophys. Res., 112, D11119, doi: 10.1029/2006JD007934. [Link]

Randel, W. J., F. Wu, and W. R. Rios, 2003: Thermal variability of the tropical tropopause region derived from GPS/MET observations. J. Geophys. Res., 108, 4024, doi: 10.1029/ 2002JD002595. [Link]

Rocken, C., R. Anthes, M. Exner, D. Hunt, S. Sokolovskiy, R. Ware, M. Gorbunov, W. Schreiner, D. Feng, B. Herman, Y. H. Kuo, and X. Zou, 1997: Analysis and validation of 
GPS/MET data in the neutral atmosphere. J. Geophys. Res., 102, 29849-29866, doi: 10.1029/97JD02400. [Link]

Rocken, C., Y. H. Kuo, W. S. Schreiner, D. Hunt, S. Sokolovskiy, and C. McCormick, 2000: COSMIC system description. Terr. Atmos. Ocean. Sci., 11, 21-52.

Salby, M. L. and P. Callaghan, 1997: Sampling error in climate properties derived from satellite measurements: Consequences of undersampled diurnal variability. J. Climate, 10, 18-36, doi: 10.1175/1520-0442(1997)010<0018: SEICPD $>2.0 . C O ; 2$. [Link]

Sausen, R. and B. D. Santer, 2003: Use of changes in tropopause height to detect human influences on climate. Meteorol. Z., 12, 131-136, doi: 10.1127/0941-2948/2003/ 0012-0131. [Link]

Schmidt, T., J. Wickert, G. Beyerle, and C. Reigber, 2004: Tropical tropopause parameters derived from GPS radio occultation measurements with CHAMP. J. Geophys. Res., 109, D13105, doi: 10.1029/2004JD004566. [Link]

Schmidt, T., G. Beyerle, S. Heise, J. Wickert, and M. Rothacher, 2006: A climatology of multiple tropopauses derived from GPS radio occultations with CHAMP and SAC-C. Geophys. Res. Lett., 33, L04808, doi: 10.1029/2005GL 024600. [Link]

Schreiner, W., C. Rocken, S. Sokolovskiy, S. Syndergaard, and D. Hunt, 2007: Estimates of the precision of GPS radio occultations from the COSMIC/FORMOSAT-3 mission. Geophys. Res. Lett., 34, L04808, doi: 10.1029/2006GL 027557. [Link]

Schroeder, T., S. Leroy, M. Stendel, and E. Kaas, 2003: Validating the microwave sounding unit stratospheric record using GPS occultation. Geophys. Res. Lett., 30, doi: 10.1029/2003GL017588. [Link]

Sherwood, S. C., J. R. Lanzante, and C. L. Meyer, 2005: Radiosonde daytime biases and late-20th century warming. Science, 309, 1556-1559, doi: 10.1126/science.1115640. [Link]

Steiner, A. K., G. Kirchengast, and H. P. Ladreiter, 1999: Inversion, error analysis, and validation of GPS/MET occultation data. Ann. Geophys., 17, 122-138, doi: 10.1007/ s005850050742. [Link]

Steiner, A. K., G. Kirchengast, U. Foelsche, L. Kornblueh, E. Manzini, and L. Bengtsson, 2001: GNSS occultation sounding for climate monitoring. Phys. Chem. Earth (A), 26, 113-124, doi: 10.1016/S1464-1895(01)00034-5. [Link]

Steiner, A. K., G. Kirchengast, M. Borsche, U. Foelsche, and T. Schoengassner, 2007: A multi-year comparison of lower stratospheric temperatures from CHAMP radio occultation data with MSU/AMSU records. J. Geophys. Res., 112, D22110, doi: 10.1029/2006JD008283. [Link]

Syndergaard, S., 1999: Retrieval analysis and methodologies in atmospheric limb sounding using the GNSS radio occultation technique, DMI Sci. Rep., 99-6, Danish Met. Inst., Copenhagen, Denmark.

Thorne, P. W., D. E. Parker, S. F. B. Tett, P. D. Jones, M. McCarthy, H. Coleman, and P. Brohan, 2005: Revisiting radiosonde upper air temperatures from 1958 to 2002. J. Geophys. Res., 110, D18105, doi: 10.1029/2004JD005753. [Link]

Vinnikov, K. Y., N. C. Grody, A. Robock, R. J. Stouffer, P. D. Jones, and M. D. Goldberg, 2006: Temperature trends at the surface and in the troposphere. J. Geophys. Res., 111, D03106, doi: 10.1029/2005JD006392. [Link]

Vorob'ev, V. V. and T. G. Krasil'nikova, 1994: Estimation of the accuracy of the atmospheric refractive index recovery from Doppler shift measurements at frequencies used in the NAVSTAR system. Phys. Atmos. Ocean, 29, 602-609.

Ware, R., M. Exner, D. Feng, M. Gorbunov, K. Hardy, B. Herman, Y. Kuo, T. Meehan, W. Melbourne, C. Rocken, W. Schreiner, S. Sokolovskiy, F. Solheim, X. Zou, R. Anthes, S. Businger, and K. Trenberth, 1996: GPS Sounding of the atmosphere from Low Earth Orbit: Preliminary results. Bull. Amer. Meteor. Soc., 77, 19-40, doi: 10.1175/ 1520-0477(1996)077<0019:GSOTAF>2.0.CO;2. [Link]

Wickert, J., C. Reigber, G. Beyerle, R. König, C. Marquardt, T. Schmidt, L. Grunwaldt, R. Galas, T. K. Meehan, W. G. Melbourne, and K. Hocke, 2001: Atmospheric sounding by GPS radio occultation: First results from CHAMP. Geophys. Res. Lett., 28, 3263-3266, doi: 10.1029/2001GL 013117. [Link]

Wickert, J., T. Schmidt, G. Beyerle, R. König, C. Reigber, and N. Jakowski, 2004: The radio occultation experiment aboard CHAMP: Operational data analysis and validation of vertical atmospheric profiles. J. Meteorol. Soc. Jpn., 82, 381-395, doi: 10.2151/jmsj.2004.381. [Link]

Wickert, J., G. Beyerle, R. König, S. Heise, L. Grunwaldt, G. Michalak, Ch. Reigber, and T. Schmidt, 2005: GPS radio occultation with CHAMP and GRACE: A first look at a new and promising satellite configuration for global atmospheric sounding. Ann. Geophys., 23, 653-658.

Wu, B. H., V. Chu, P. Chen, and T. King, 2005: FORMOSAT-3/ COSMIC science mission update. GPS Solut., 9, 111-121, doi: 10.1007/s10291-005-0140-z. [Link]

Yuan, L. L., R. A. Anthes, R. H. Ware, C. Rocken, W. D. Bonner, M. G. Bevis, and S. Businger, 1993: Sensing climate change using the Global Positioning System. J. Geophys. Res., 98, 14925-14937, doi: 10.1029/93JD00948. [Link]

Yunck, T. P., C. H. Liu, and R. Ware, 2000: A history of GPS sounding. Terr. Atmos. Ocean. Sci., 11, 1-20. 